\title{
New Naturally Occurring Compounds from Sarcophyton trocheliophorum
}

\author{
Mohamed Shaaban ${ }^{1,2}$ (D), Mohamed A. Ghani ${ }^{3}$, Marwa Y. Issa ${ }^{4, *}$ (D) \\ 1 Institute of Organic and Biomolecular Chemistry, University of Göttingen, Tammannstrasse 2,D-37077 Göttingen, \\ Germany; mshaaba@gmail.com (M.S.); \\ 2 Chemistry of Natural Compounds Department, Division of Pharmaceutical Industries, National Research Centre, El- \\ Behoos st. 33, Dokki-Cairo 12622, Egypt \\ 3 Red Sea Marine Parks, P.O. Box 363, Hurghada, Red Sea, Egypt; mabdelghany@ hotmail.com (M.A.G.); \\ 4 Pharmacognosy Department, Faculty of Pharmacy, Kasr El-Aini St., Cairo 11562, Egypt; marwa.issa@ pharma.cu.edu.eg \\ (M.Y.I.); \\ * Correspondence: marwa.issa@ pharma.cu.edu.eg (M.Y.I.);
}

Scopus Author ID 57200552012

Received: 4.03.2021; Revised: 5.05.2021; Accepted: 9.05.2021; Published: 18.06.2021

\begin{abstract}
Corals are rich sources of secondary metabolites used as chemical defense compounds against predators. The production of diverse metabolites has characterized soft corals belonging to the genus Sarcophyton. However, phenolic compounds are slightly rare in soft corals. Through a further bioassay-guided fractionation for the chloroform-soluble extract of soft coral Sarcophyton trocheliophorum, collected from the Red Sea, three closely related phenolic compounds: 2,4-di-tertbutyl-6-nitro-phenol (1), 2,4-di-tert-butyl-phenol (2), and 2,4-bis(1-methyl-1-phenylethyl)-phenol (3), along with the wax tricosyldocosanoiate (4) were isolated herein for the first time from nature in addition to cholesterol. Structures of the isolated compounds 1-4 were identified by NMR spectroscopy $\left({ }^{1} \mathrm{H},{ }^{13} \mathrm{C},{ }^{1} \mathrm{H},{ }^{1} \mathrm{H}\right.$ COSY, HMQC and HMBC) and mass spectrometry (EI, HRESI-MS) for the first time so far. The antimicrobial activities of the soft coral extract, along with the isolated compounds, were evaluated against Staphylococcus aureus, Bacillus subtilis ATCC6051, Streptomyces viridochromogenes Tü 57, Escherichia coli, Mucor miehei Tü 284, Candida albicans, and the green alga Chlorella vulgaris. The crude extract exhibited a moderate activity against Streptomyces viridochromogenes Tü $57(12 \mathrm{~mm})$ at a concentration of $400 \mu \mathrm{g} / \mathrm{disc}$, while the reported compounds 14 showed no activity against the reported test microorganisms at a concentration of $40 \mu \mathrm{g} / \mathrm{disc}$.
\end{abstract}

Keywords: Naturally new phenolic compounds; tricosyldocosanoiate; Sarcophyton trocheliophorum; biological activities.

(C) 2021 by the authors. This article is an open-access article distributed under the terms and conditions of the Creative Commons Attribution (CC BY) license (https://creativecommons.org/licenses/by/4.0/).

\section{Introduction}

Corals are rich sources of secondary metabolites used as chemical defense compounds to deter predators [1]. Soft corals belonging to the genus Sarcophyton have been characterized by the production of diverse terpenoidal compounds, namely, cembranoid diterpenes, furanoditerpenes, along with norditerpenes and sesquiterpenes [2-11]. Besides, they are predominantly rich in several lipid classes, including fatty acids, waxes, monoalkyl, diacylglycerols, triacylglycerols, sterols, and different species of phospholipids and ceramide aminoethyl phosphonate (CAEP). In contrast, phenolic compounds are slightly rare in soft corals. 
As a continuation to our previous searching for diverse bioactive metabolites from Sarcophyton trocheliophorum, collected from Red Sea [6, 7], three phenolic metabolites: 2,4di-tert-butyl-6-nitro-phenol (1), 2,4-di-tert-butyl-phenol (2), 2,4-bis(1-methyl-1-phenylethyl)phenol (3) in addition to the wax tricosyldocosanoiate (4) were isolated herein for the first time from natural sources so far (Figure 1). The obtained compounds 1-4 were definitely assigned using intensive studies of NMR spectroscopy $\left({ }^{1} \mathrm{H},{ }^{13} \mathrm{C},{ }^{1} \mathrm{H},{ }^{1} \mathrm{H}\right.$ COSY, HMQC, and HMBC) and mass spectrometry (EI, HRESI-MS) for the first time as well. The antimicrobial activity of the reported compounds was investigated against a set of diverse pathogenic microorganisms.

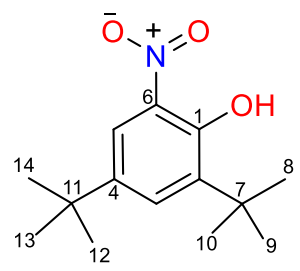

1

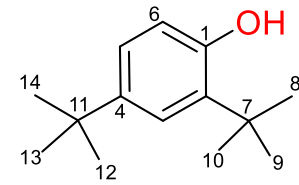

2

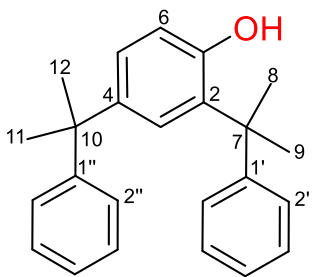

3

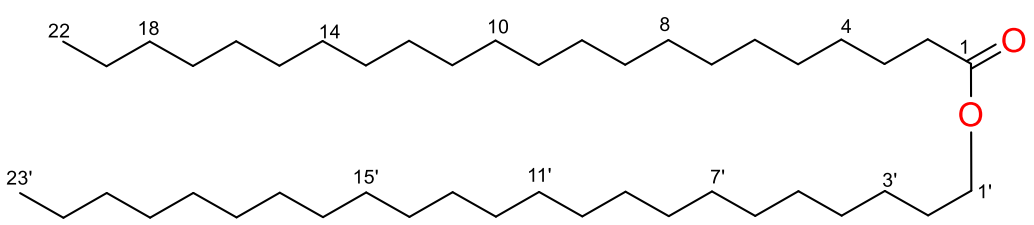

4

Figure 1. Structures of compounds $1-4$.

\section{Materials and Methods}

\subsection{Apparatus and techniques.}

The NMR spectra were measured on Varian (Palo Alto, CA, USA) Unity 300 (300.145 $\mathrm{MHz}$ ) and Varian Inova $500(125.7 \mathrm{MHz})$ spectrometers. HR-ESIMS was recorded by ESI MS on an Apex IV 7 Tesla FT Ion Cyclotron Resonance MS (Bruker Daltonics, Billerica, MA, USA). EI-MS spectra were recorded on a Finnigan MAT 95 spectrometer $(70 \mathrm{eV})$ with perfluorkerosine as a reference substance for EI HRMS. HRMS were recorded by ESI MS on an Apex IV 7 Tesla Fourier-Transform Ion Cyclotron Resonance Mass Spectrometer (Bruker Daltonics, Billerica, MA, USA). Flash chromatography was performed on silica gel (230-400 mesh). Size exclusion chromatography was carried out on Sephadex LH-20 (Lipophilic Sephadex, Amersham Biosciences Ltd; purchased from Sigma-Aldrich Chemie, Steinheim, Germany). $R_{\mathrm{f}}$ values were measured on Polygram SIL G/UV 254 TLC sheets (Macherey-Nagel).

\subsection{Extraction, isolation, and purification.}

The methodology of extraction of the soft coral Sarcophyton trocheliophorum (1800 g, wet) and working up was carried out as similar as to our recently reported work [12], affording $46.17 \mathrm{~g}$ of a yellowish-brown crude extract. The crude extract was then applied to prefractionation on silica gel column $(100 \times 5 \mathrm{~cm})$ and eluted with $n$-hexane followed by a gradual increase of the polarity using a subsequent addition of dichloromethane (DCM) and then methanol, affording 16 fractions. Re-monitoring of the obtained fractions using TLC and 
visualization by UV and anisaldehyde/sulphuric acid reduced them into eight fractions. The non-polar fractions FI (7.8 g), FII (5.2 g), and FIII (3.2 g) were re-combined according to their TLC similarity and applied to a series of subsequent chromatographic purifications, starting with silica gel column chromatography $(100 \times 3 \mathrm{~cm})$ and elution with $\mathrm{n}$-hexane followed by a polarity gradual increasing using DCM. This afforded a colorless solid (200 mg) of tricosyl docosanoiate (4), and the latter was washed by methanol, affording $170 \mathrm{mg}$ as pure colorless solid. A further yellow impure compound was obtained, which was purified using preparative TLC (cyclohexane/DCM/1: 1) and the Sephadex LH-20 (DCM/40\% MeOH) to give $6 \mathrm{mg}$ of 2,4-di-tert-butyl-6-nitro-phenol (1) as bright yellow solid. Continuing purification of the remaining sub-fractions using two individual silica gel columns $(20 \times 1 \mathrm{~cm})$ and elution with cyclohexane-DCM gradient, and then Sephadex LH-20 (DCM/40\% $\mathrm{MeOH}$ ) resulted in colorless amorphous compounds 2,4-di-tert-butyl-phenol (2, $7 \mathrm{mg})$ and 2,4-bis(1-methyl-1phenylethyl)-phenol $(\mathbf{3}, 18 \mathrm{mg})$ and colorless solid of cholesterol (50 mg).

\subsubsection{2,4-Di-tert-butyl-6-nitro-phenol (1).}

Yellow solid, UV absorbing (254 nm), turned faint blue on spraying with anisaldehyde/sulphuric acid and heating; $R_{\mathrm{f}}=0.42$ (cyclohexane/20\% $\mathrm{CH}_{2} \mathrm{Cl}_{2}$ ); ${ }^{1} \mathrm{H}$ NMR (300 $\left.\mathrm{MHz}, \mathrm{CDCl}_{3}\right)$ and ${ }^{13} \mathrm{C} \mathrm{NMR}\left(125 \mathrm{MHz}, \mathrm{CDCl}_{3}\right)$ see Table $1 ;(+)$ ESI MS: $m / z(\%) 274$ $\left([\mathrm{M}+\mathrm{Na}]^{+}\right),(-) \mathrm{ESI} \mathrm{MS}: \mathrm{m} / z(\%) 250\left([\mathrm{M}-\mathrm{H}]^{-}\right) ;(-)-\mathrm{ESI}-\mathrm{HRMS}: \mathrm{m} / z$ 250.14481 [M-H] (calc: 250.14485 for $\left.\mathrm{C}_{14} \mathrm{H}_{20} \mathrm{NO}_{3}\right)$

\subsubsection{2,4-Di-tert-butyl-phenol (2).}

Colourless amorphous, UV absorbing $(254 \mathrm{~nm})$, stained intense pink-violet on spraying with anisaldehyde/sulphuric acid and heating, turned later as blue; $R_{\mathrm{f}}=0.50$ (cyclohexane $/ 20 \%$ $\left.\mathrm{CH}_{2} \mathrm{Cl}_{2}\right) ;{ }^{1} \mathrm{H}$ NMR $\left(300 \mathrm{MHz}, \mathrm{CDCl}_{3}\right)$ and ${ }^{13} \mathrm{C} \mathrm{NMR}\left(125 \mathrm{MHz}, \mathrm{CDCl}_{3}\right.$ ) see Table 2; EI MS: $m / z(\%) 206.2\left([\mathrm{M}]^{+}, 10\right), 192.2\left(\left[\mathrm{M}-\mathrm{CH}_{2}\right]^{+}, 9\right), 191.2\left(\left[\mathrm{M}-\mathrm{CH}_{3}\right]^{+}, 57\right), 175.1(5), 163.1(7)$, 91.1 (10), 48.0 (25), 43.0 (100); (-)ESI MS: m/z (\%) 205.2 ([M-H]') HREI MS: 206.16649 $\left([\mathrm{M}]^{-}\right)\left(\right.$Calc: 206.16652 for $\left.\mathrm{C}_{14} \mathrm{H}_{22} \mathrm{O}\right)$

\subsubsection{2,4-Bis(1-methyl-1-phenylethyl)-phenol (3).}

Colourless amorphous, UV absorbing $(254 \mathrm{~nm})$, stained intense pink-violet on spraying with anisaldehyde/sulphuric acid and heating, turned later as blue; $R_{\mathrm{f}}=0.54$ (cyclohexane $/ 20 \%$ $\mathrm{CH}_{2} \mathrm{Cl}_{2}$ ); ${ }^{1} \mathrm{H}$ NMR $\left(300 \mathrm{MHz}, \mathrm{CDCl}_{3}\right.$ ) and ${ }^{13} \mathrm{C} \mathrm{NMR}\left(125 \mathrm{MHz}, \mathrm{CDCl}_{3}\right.$ ) see Table 2; EI MS: $m / z(\%) 330.2\left([\mathrm{M}]^{+}, 43\right) ; 315.2\left(\left[\mathrm{M}-\mathrm{CH}_{3}\right]^{+}, 100\right), 237.2$ (34), 119 (22), 103 (15), 91 (27), 77 (14); (-)ESI MS: $m / z(\%) 329.2\left([\mathrm{M}-\mathrm{H}]^{-}\right)$; HREI MS: $330.19783\left([\mathrm{M}]^{+}\right)$(Calc: 330.19781 for $\left.\mathrm{C}_{14} \mathrm{H}_{22} \mathrm{O}\right)$.

\subsubsection{Tricosyldocosanoiate (4).}

Colourless solid, UV non-absorbing (254 nm) or fluorescence ( $366 \mathrm{~nm})$, showed bright blue staining on spraying with anisaldehyde/sulphuric acid and heating; $R_{\mathrm{f}}=0.65$ (cyclohexane/80\% $\mathrm{CH}_{2} \mathrm{Cl}_{2}$ ); ${ }^{1} \mathrm{H}$ NMR $\left(300 \mathrm{MHz}, \mathrm{CDCl}_{3}\right)$ and ${ }^{13} \mathrm{C} \mathrm{NMR}\left(125 \mathrm{MHz}, \mathrm{CDCl}_{3}\right)$ see Table 3; (+)ESI MS: $m / z(\%) 663\left([\mathrm{M}+\mathrm{H}]^{+}\right)$; EI MS: $m / z(\%) 662.5\left([\mathrm{M}]^{+}, 29.5\right), 648.5$ ([M-CH$\left.]^{+}, 41\right), 647.5\left(\left[\mathrm{M}-\mathrm{CH}_{3}\right]^{+}, 91\right), 591.4$ (9), 554.4 (7), 536.6 (23), 530.5 (14), 515.5 (9), 509.6 (34), 508.6 (100); HREI MS: $m / z 662.6939$ [M] ${ }^{+}$(calc: 662.6935 for $\mathrm{C}_{45} \mathrm{H}_{90} \mathrm{O}_{2}$ ). 


\subsection{Antimicrobial assay using the agar diffusion test.}

Antimicrobial assays using the agar disc diffusion method were done as previously reported [13]. The test strains: M. miehei Tü 284 and Streptomyces viridochromogenes Tü 57 were provided from the collection of Prof. H. Zähner (University of Tübingen, Germany), and Chlorella vulgaris was provided by the Algensammlung Göttingen. B. subtilis ATCC 6051 was acquired from the American Type Culture Collection, whereas E. coli, C. albicans and $S$. aureus are clinical isolates from Göttingen hospitals. Strains are preserved in the strain collection Prof. Laatsch, Institute of Organic and Biomolecular Chemistry, Georg-August University, Göttingen, Germany.

\section{Results and Discussion}

The unipolar fraction acquired from the chloroform extract of the soft coral Sarcophyton trocheliophorum was investigated using a sequence of chromatographic techniques to give compounds 1-4 and cholesterol. Details of structure elucidation of the desired compounds along with their reported biological studies and chemistry, are shown below.

\subsection{Structural identification.}

\subsubsection{2,4-Di-tert-butyl-6-nitro-phenol.}

Compound 1 was obtained as bright yellow solid, showing an extremely non-polar faint yellow band on TLC, which turned faint blue on spraying with anisaldehyde/sulphuric acid. The compound was isolated by applying the fraction to the silica gel column eluted with cyclohexane and then purified on Sephadex LH-20. The molecular weight of 1 was established as 251 Dalton (Figure S1 and S2), and the corresponding molecular formula was $\mathrm{C}_{14} \mathrm{H}_{21} \mathrm{NO}_{3}$, bearing five double bond equivalents.

The ${ }^{1} \mathrm{H}$ NMR (Figure S3 and S4) of 1 displayed a singlet of $1 \mathrm{H}$ at $\delta 11.42$, being for a phenolic hydroxyl group, two aromatic signals each of $1 \mathrm{H}$ with an $m$-coupling property $(J 2.5)$ at $\delta 7.96$ and 7.63, meanwhile, two singlets each of $9 \mathrm{H}$ were exhibited at $\delta 1.42$ and 1.35, respectively, corresponding to two equivalent sets of tertiary butyl groups. Based on the ${ }^{13} \mathrm{C}$ NMR (Figure S5) and HMQC (Figure S8) experiment of compound 1, ten carbon signals (integrated for 14 carbons) were revealed, which were classified into four $s p^{2}$ quaternary carbons $(\delta 152.9,141.8,139.8$, and 133.5$)$, two $s p^{2}$ methine carbons $\left(\delta 132.5\right.$ [ $\left.\delta_{\mathrm{H}}: 7.63\right], 118.8$ $[\delta \mathrm{H}: 7.96])$, two quaternary $s p^{3}$ carbons $(\delta 35.8,34.6)$ and two $s p^{3}$ proton bounded-carbons $(\delta$ 31.2 [ $\delta \mathrm{H}: 1.34], 29.4[\delta \mathrm{H}: 1.42])$ each is corresponding to three methyls.

A subsequent structure confirmation of 1 was deduced based on $\mathrm{H}, \mathrm{H}$ COSY (Figure S6), HSQC (Figure S7) and HMBC (Figure S9) experiments, at where an aromatic residue containing two $m$-coupled protons (H-3, H-5), one hydroxyl group (1-OH), two tertiary butyl groups (2,4-ditert-butyl) was established, constructing $\mathrm{C}_{14} \mathrm{H}_{21} \mathrm{O}$ empirical formula. In contrast, the remaining $\mathrm{NO}_{2}$ residue has been deduced to be at C-6 (133.5) position. Hence, structure 1 was finally concluded as 2,4-di-tert-butyl-6-nitrophenol, which was isolated from nature for the first time. Meanwhile, the compound was reported in drinking water during the plastic water pipes only by GC-MS [14]. Additionally, compound 1 was reported synthetically according to Schopfer et al. (2009) [15] by treatment of oxy-heme complex with nitrogen monoxide in the presence of 2,4-di-tert-butyl-phenol as a side product along with the 
corresponding complex nitrate-iron(III). Compound $\mathbf{1}$ was obtained synthetically as well by nitration of 2,4-di-tert-butyl-phenol in acetic anhydride or chloroform [16].

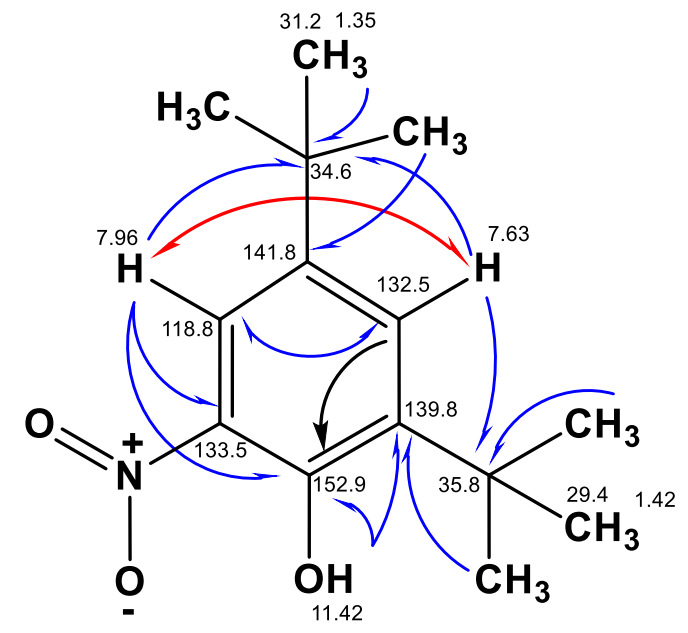

Figure 2. ${ }^{1} \mathrm{H},{ }^{1} \mathrm{H} \operatorname{COSY}(\curvearrowleft)$ and $\mathrm{HMBC}(\neg)$ correlations of 2,4-di-tert-butyl-6-nitro-phenol (1).

Table 1. ${ }^{13} \mathrm{C}\left(125 \mathrm{~Hz}, \mathrm{CDCl}_{3}\right)$ and ${ }^{1} \mathrm{H}\left(300 \mathrm{MHz}, \mathrm{CDCl}_{3}\right)$ NMR data of the phenolic compounds 1 and 2.

\begin{tabular}{|c|c|c|c|c|}
\hline \multirow[t]{2}{*}{ Position } & \multicolumn{2}{|r|}{1} & \multicolumn{2}{|l|}{2} \\
\hline & $\delta \mathrm{C}$ & $\delta_{\mathrm{H}}(J$ in $\mathrm{Hz})$ & $\delta \mathrm{C}$ & $\delta_{\mathrm{H}}(J$ in $\mathbf{H z})$ \\
\hline 1 & 152.9 & - & 151.6 & - \\
\hline $1-\mathrm{OH}$ & - & $11.42(\mathrm{~s})$ & & \\
\hline 2 & 139.8 & - & 135.0 & \\
\hline 3 & 132.5 & $7.63(\mathrm{~d}, 2.5)$ & 124.0 & $7.30(\mathrm{~m})$ \\
\hline 4 & 141.8 & - & 142.8 & \\
\hline 5 & 118.8 & $7.96(\mathrm{~d}, 2.5)$ & 123.4 & $7.07(\mathrm{dd}, 8.2,2.5)$ \\
\hline 6 & 133.5 & - & 115.8 & $6.58(\mathrm{~d}, 8.2)$ \\
\hline 7 & 35.8 & - & 34.8 & \\
\hline $8,9,10$ & 29.4 & $1.42(\mathrm{~s})$ & 29.7 & $1.42(\mathrm{~s})$ \\
\hline 11 & 34.6 & - & 34.3 & \\
\hline $12,13,14$ & 31.2 & $1.35(\mathrm{~s})$ & 31.7 & $1.30(\mathrm{~s})$ \\
\hline
\end{tabular}

\subsubsection{2,4-Di-tert-butyl-phenol.}

Compound 2 was obtained as colorless amorphous with low polarity, showing a UV absorbing band $(254 \mathrm{~nm})$ on TLC, turned as intense pink-violet on spraying with anisaldehyde/sulphuric acid and heating, turned later as blue. The molecular weight of 2 was confirmed as 206 Dalton (Figure S10 and 11), and the corresponding molecular formula as $\mathrm{C}_{14} \mathrm{H}_{22} \mathrm{O}$, bearing four double bond equivalents.

The ${ }^{1} \mathrm{H}$ NMR (Figure S12 and S13) of $\mathbf{2}$ showed three aromatic protons were exhibited at $\delta 7.30,7.07$, and 6.58, being for 1,2,4-trisubstituted aromatic residue. In the aliphatic region, two singlets were visible $\delta 1.42$ and 1.30 , each with the integration of three methyls. The ${ }^{13} \mathrm{C}$ NMR (Figure S14) and HMQC (Figure S16) experiment (Table 3) of compound 2 confirmed the existence of ten carbon signals equivalent to 14 carbons, classified into one phenolic signal at 151.6 , two $s p^{2}$ quaternary carbons $(142.8,135.0)$, two $s p^{3}$ quaternary carbons $(34.8,34.3)$ and two signals at 31.7 and 29.7 each equivalent to three methyl groups, confirming the existence of two tert-butyl groups.

A subsequent structure study of compound 2 using H,H COSY (Figure S15), and HMBC (Figure S17) experiments (Figure 3) was investigated, at where the two tert-butyl groups were deduced to be attached in $m$-positions with respect to each other on the phenolic residue at 2- and 4- positions, respectively. Further confirmation to such conclusion was 
attributed to the shown HMBC correlations from the first set the three singlet methyls $\left(\mathrm{H}_{3}-\right.$ $8,9,10, \delta 1.42)$ at C-2 $\left(135.0,{ }^{3} J\right)$ and C-7 $\left(34.8,{ }^{3} J\right)$ and each other (C-8,9,10, $\left.\delta 29.7\right)$, meanwhile the second set of the tert-methyl group $\left(\mathrm{H}_{3}-12,13,14, \delta 1.30\right)$ showed correlations at C-4 (142.8), C-11 (34.3), and each other as well (C-12,134,14, $\delta$ 31.7). Moreover, the aromatic proton $\mathrm{H}-3$ (7.30) proved a further attachment between the corresponding two tertbutyl groups at C-2 and C-4, respectively, via a ${ }^{3} J$ HMBC correlation at C-7 (34.8) and C-11 (34.3). More confirmation of structure 2 based on HMBC and H, H COSY correlations are shown in Figure 3. In accordance, compound 2 was assigned as 2,4-di-tert-butyl-phenol.

Compound 2 was only reported during a GC-MS analysis for the chemical dyestuff of wastewater [17]. Naturally, compound 2 was detected too by GC-MS as a volatile constituent in herbal pair Flos Lonicerae-radix Glycyrrhizae and its single herbs [18]; fat-soluble constituent in pine cone of Pinus yunnanensis from various habitats [19], fatty acids of Cordyceps cicadae Shing [20], essential oil of the Abutilon indicum (L.) [21], fat-soluble constituent in flowers of Tibetan medicinal plants of Gentiana species [22] and numerous various plant species [23-25], the marine sponge Zygomycale sp. [26], algae Dictyopteris membranaceae and Cystoseira barbata [27], polluted terrestrial and marine waters [28], and microorganisms [29].

Biologically, compound 2 has a slight inhibition effect on anaerobic microbes at 13.14$40.56 \mathrm{mg} / \mathrm{L}$, while it has a moderate inhibition effect at $40.56-152.41 \mathrm{mg} / \mathrm{L}$, and serious inhibition effect when the concentration of 2,4-di-tert-butyl-phenol is higher than $152.41 \mathrm{mg} / \mathrm{L}$, and the median effective concentration $\left(\mathrm{EC}_{50}\right)$ was reported at $49.61 \mathrm{mg} / \mathrm{L}$. The aerobic toxicity of 2,4-di-tert-butyl-phenol is higher than the anaerobic toxicity with the concentration of 0-250 $\mathrm{mg} / \mathrm{L}$, while the anaerobic toxicity of 2,4-di-tert-butyl-phenol is higher than the aerobic toxicity at concentrations higher than $>250 \mathrm{mg} / \mathrm{L}$ [30]. Compound 2 was reported to show effective activity against Staphylococcus aureus, Candida albicans, and fungi [31, 32], in addition to its reported antioxidant and anti-inflammatory activities [33-35]. Additionally, it showed significant activity against Aspergillus niger [36] and possessed very remarkable cytotoxic activity against $\mathrm{KB}$ cells, with an $\mathrm{IC}_{50}$ of $0.81 \mu \mathrm{g} / \mathrm{mL}$ [37].

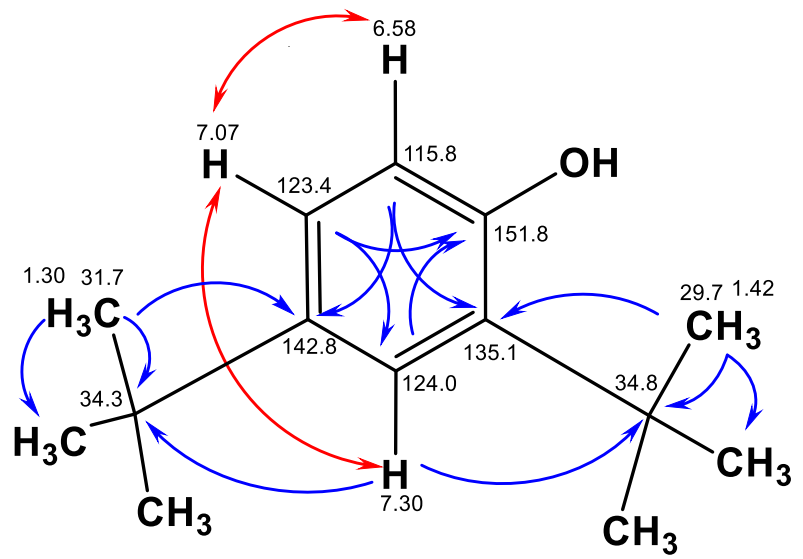

Figure 3. ${ }^{1} \mathrm{H},{ }^{1} \mathrm{H}$ COSY $(\curvearrowleft)$ and $\operatorname{HMBC}(\neg)$ correlations of 2,4-di-tert-butyl-phenol (2).

\subsubsection{2,4-Bis (1-methyl-1-phenylethyl)-phenol.}

Compound $\mathbf{3}$ was obtained as colorless amorphous, showing similar chromatographic properties to $\mathbf{2}$. The molecular weight of $\mathbf{3}$ was confirmed as 330 Dalton (Figure S18-S20), and the corresponding molecular formula as $\mathrm{C}_{24} \mathrm{H}_{26} \mathrm{O}$, bearing twelve double bond equivalents. The 
${ }^{1} \mathrm{H}$ NMR (Figure S21 and S22) of 3 showed three aromatic protons at $\delta 7.33,7.02$, and 6.64, characteristic identically to a 1,2,4-trisubstituted aromatic residue. Further, ten aromatic protons, representing two phenyl groups, were visible in the region between $\delta 7.32 \sim 7.18$. In the aliphatic region, two singlets were visible $\delta 1.72$ and 1.61 each with the integration of two methyls. The ${ }^{13} \mathrm{C}$ NMR (Figure S23) and HMQC (Figure S25) experiment (Table 3) of compound 3 confirmed the existence of twenty carbon signals equivalent to 24 carbons, classified into one phenolic signal $(\delta 151.4)$, four $s p^{2}$ quaternary carbons $(\delta 151.0,148.2,142.5$ and 134.3), thirteen methine carbons $(\delta 129.0 \sim 124.7)$, two $s p^{3}$ quaternary carbons $(\delta 42.7$, $41.8)$ and two signals ( $\delta 31.1$ and 29.6) corresponding to four methyl carbons.

A subsequent structure study of compound 3 using H, H COSY (Figure S24), and HMBC (Figure S26) experiments (Figure 4) confirmed the attachment of two benzyl groups in $m$-positions with respect to each other on the phenolic residue at C-2 and C-4, respectively. The first set of the two singlet methyls (1.61) showed HMBCs versus C-2 (134.3), C-7 (41.8), C-1' (148.2), confirming their geminal location at C-7. Meanwhile, the second set of methyl groups exhibited HMBCs towards C-4 (142.5), C-10 (42.7), C-1" (151.0), deducing their geminal position at $\mathrm{C}-10$. In addition, the aromatic proton $\mathrm{H}-3(\delta 7.33)$ further proved the connection between the corresponding two benzyl groups via a ${ }^{3} \mathrm{~J}$ HBC correlation at $\mathrm{C}-2$ and C-4, respectively. Further HMBC and H, H COSY correlations are shown in Figure 4. In accordance, compound $\mathbf{3}$ was undoubtedly assigned as 2,4-bis(1-methyl-1-phenylethyl)phenol. Compound $\mathbf{3}$ was reported only by GC-MS as a constituent of Metasequoia glyptostroboides (Taxodiaceae), the solitary species in the genus Metasequoia [38], and from Dioscorea hypoglauca [39]. Compound 3 was represented as one of the components having antitumor and antibacterial activities [37].

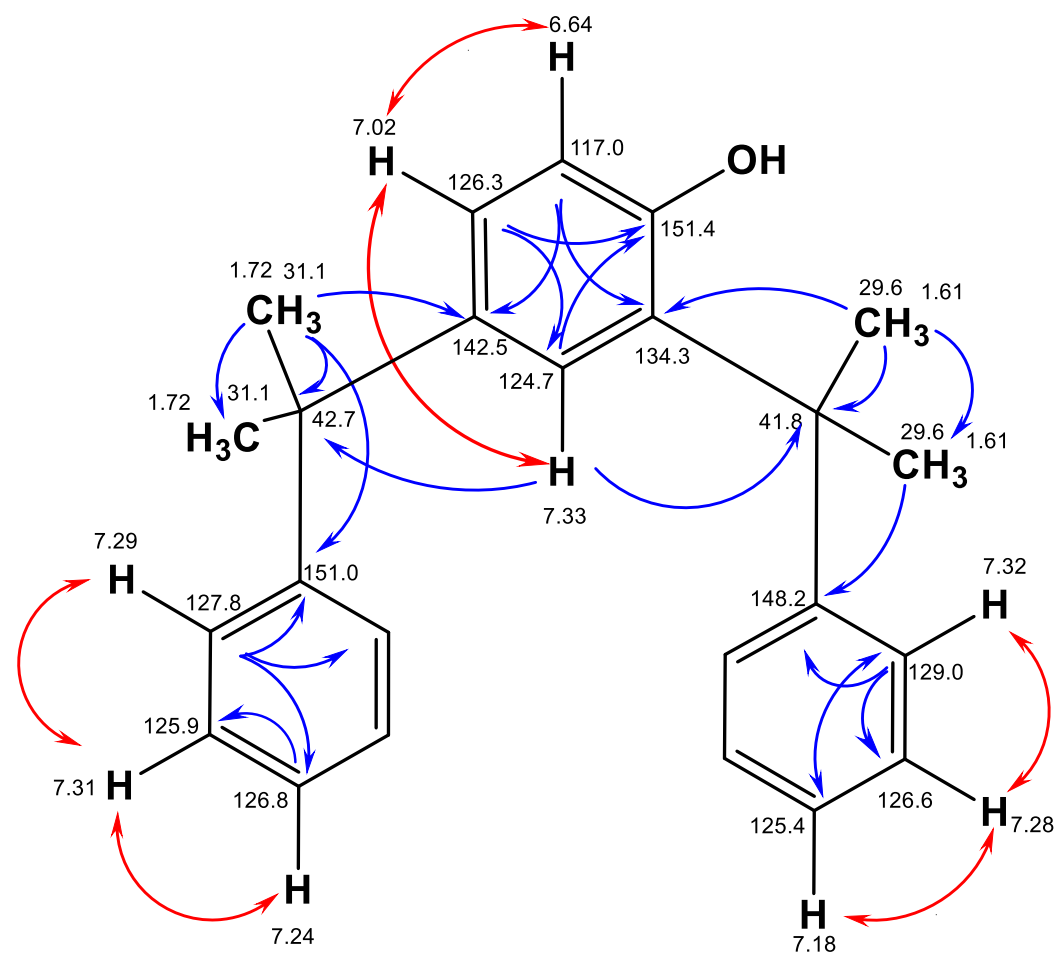

Figure 4. ${ }^{1} \mathrm{H},{ }^{1} \mathrm{H} \operatorname{COSY}(\curvearrowleft)$ and $\mathrm{HMBC}(\frown)$ correlations of 2,4-bis (1-methyl-1-phenylethyl)-phenol (3).

Table 2. ${ }^{13} \mathrm{C}(125 \mathrm{MHz})$ of and ${ }^{1} \mathrm{H}$ NMR $\left(300 \mathrm{MHz}, \mathrm{CDCl}_{3}\right)$ of 2,4-bis (1-methyl-1-phenylethyl)-phenol (3).

\begin{tabular}{llllll}
\hline Position & $\boldsymbol{\delta} \mathbf{C}$ & $\boldsymbol{\delta} \mathbf{H}(\boldsymbol{J}$ in $\mathbf{H z})$ & Position & $\boldsymbol{\delta} \mathbf{C}$ & $\boldsymbol{\delta}_{\mathbf{H}}(\boldsymbol{J} \mathbf{~ i n ~} \mathbf{H z})$ \\
\hline 1 & 151.4 & & $1^{\prime}$ & 148.3 & \\
2 & 134.3 & & $2^{\prime}, 6^{\prime}$ & 129.0 & $7.32(\mathrm{~m})$
\end{tabular}




\begin{tabular}{|c|c|c|c|c|c|}
\hline Position & $\delta \mathrm{C}$ & $\delta \mathrm{H}(J$ in $\mathrm{Hz})$ & Position & $\delta \mathrm{C}$ & $\delta \mathrm{H}(J$ in $\mathrm{Hz})$ \\
\hline 3 & 124.7 & $7.33(\mathrm{~m})$ & $3^{\prime}, 5^{\prime}$ & 126.6 & $7.28(\mathrm{~m})$ \\
\hline 4 & 142.5 & & $4{ }^{\prime}$ & 125.4 & $7.18(\mathrm{~m})$ \\
\hline 5 & 126.3 & $7.02(\mathrm{dd}, 8.3,2.4)$ & $1 "$ & 151.0 & \\
\hline 6 & 117.0 & $6.64(\mathrm{~d}, 8.2)$ & $2 ", 6 "$ & 127.8 & $7.29(\mathrm{~m})$ \\
\hline 7 & 41.8 & & $3 ", 5 "$ & 125.9 & $7.31(\mathrm{~m})$ \\
\hline 8,9 & 29.6 & $1.62(\mathrm{~s})$ & $4 "$ & 126.8 & $7.24(\mathrm{~m})$ \\
\hline 10 & 42.6 & & & & \\
\hline 11,12 & 31.1 & $1.72\left(\mathrm{~s}, \mathrm{CH}_{3}\right)$ & & & \\
\hline
\end{tabular}

\subsubsection{Tricosyldocosanoiate.}

Compound 4 was obtained as an abundant colorless solid, having an extremely low polarity and insoluble property in protic solvents (e.g., methanol and water). During TLC, compound 4 showed neither UV absorbance $(254 \mathrm{~nm})$ nor fluorescence $(365 \mathrm{~nm})$; however, it displayed bright blue staining with anisaldehyde/sulphuric acid and heating. The molecular weight of 4 was confirmed as 662 Dalton (Figure S27 and S28) by EI MS, and the corresponding molecular formula is $\mathrm{C}_{45} \mathrm{H}_{90} \mathrm{O}_{2}$, displaying a sole double bond equivalent.

The ${ }^{1} \mathrm{H}$ NMR (Figure S29 and S30) of 4 displayed no aromatic or olefinic signals. Meanwhile, the whole proton signals were concentrated in the aliphatic region $(\delta 4.03 \sim 0.88$ ppm). Particularly, two triplet methylene signals were shown at $\delta 4.03$ and 2.26 being for oxyand $s p^{2}$-bounded methylenes, respectively. Furthermore, one multiplet of $4 \mathrm{H}$ integration being for two methylenes ( $\delta 1.59)$, a huge broad multiplet signal $(\delta 1.29-1.22)$ being for 38 methylene groups, terminated by multiplet $6 \mathrm{H}$ signal of two methyl groups $(\delta 0.88)$, were exhibited.

According to the ${ }^{13} \mathrm{C}$ NMR (Figure S31), HSQC (Figure S33) and HMQC (Figure S34) experiment (Table 3), compound 4 revealed one carbonyl group of ester ( $\delta 173.8)$, an $s p^{3}$ of oxymethylene ( $\delta$ 64.4), $s p^{2}$-bounded methylene $(\delta 34.5)$, signal for two-terminal methyl carbons $(\delta 14.2)$, in addition to several methylene carbon signals characteristic for an elongated methylene chain length were in the region of $\delta 32.0-22.8$, corresponding to forty methylene carbons (Table 3). Accordingly, an alcoholic fatty acid ester nature for compound 4 was concluded. A consequent study of structure 4 based on the H,H COSY (Figure S32), and HMBC (Figure S35) experiments (Figure 5) confirmed it as tricosyldocosanoiate. Compound 4 was only detected by GC-MS in Cereus peruvianus [40] and green tobacco leaf [41]. However, the compound was not reported previously from soft corals or any other marine organisms.

Soft corals are rich in different lipid classes, predominantly including fatty acids (FA), waxes, monoalkyl, diacylglycerols, triacylglycerols, sterols, and polar lipids. Acids 16:0, $18: 3 n-6,20: 4 n-6,20: 5 n-3,8: 4 n-3$ 18:5n-3, 24:5n-6 and 24:6n-3 are the most common in such lipids. Species of phospholipids and ceramide aminoethyl phosphonate (CAEP) were determined in soft corals as well [42]. Phosphonosphingolipids, namely ceramide aminoethyl phosphonate (CAEPn) and ceramide N-methylaminoethylphosphonate (CMAEPn), have been characterized in a wide variety of marine invertebrates, especially ciliated protozoa, coelenterates, gastropods, and bivalves, sometimes accompanied by small amounts of $\mathrm{N}$ methylaminoethyl, $N, N$-dimethylaminoethyl and choline analogs, that seemed to be the most widespread phosphonolipid in nature [43]. 


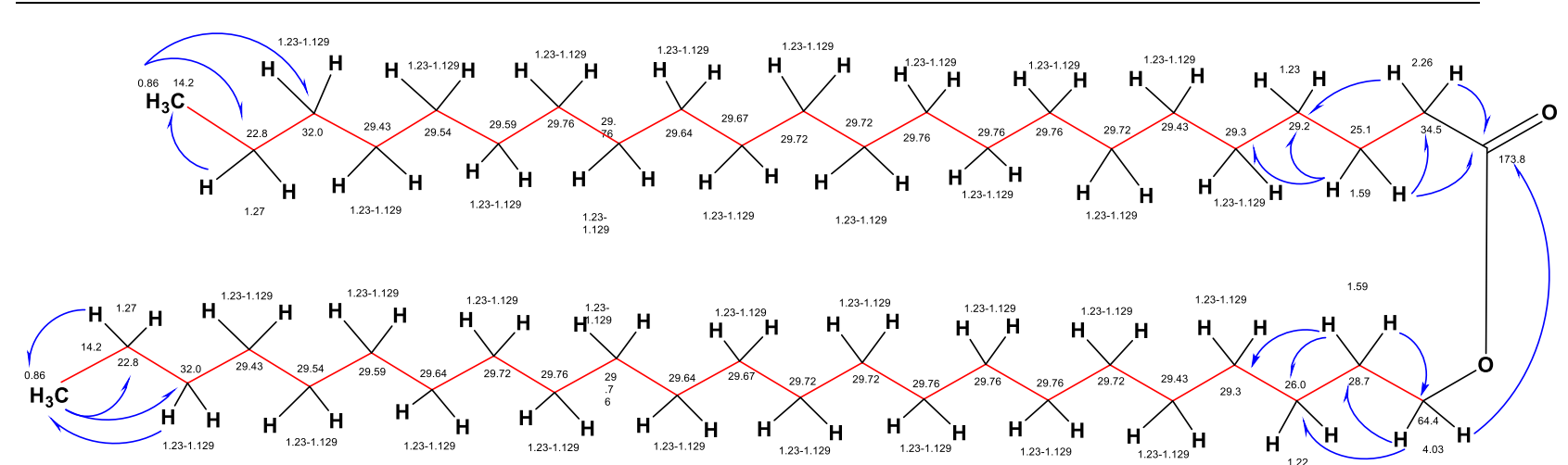

Figure 5. ${ }^{1} \mathrm{H},{ }^{1} \mathrm{H} \operatorname{COSY}(-)$ and $\mathrm{HMBC}(\frown)$ correlations of tricosyl docosanoiate (4).

Table 3. ${ }^{13} \mathrm{C}(125 \mathrm{MHz})$ of and ${ }^{1} \mathrm{H}$ NMR $\left(300 \mathrm{MHz}, \mathrm{CDCl}_{3}\right)$ of tricosyl docosanoiate (4).

\begin{tabular}{|c|c|c|c|c|c|}
\hline Position & $\delta \mathrm{C}$ & $\delta_{\mathrm{H}} J$ in $\left.\mathrm{Hz}\right)$ & Position & $\delta \mathrm{C}$ & $\delta \mathrm{H}(J$ in $\mathrm{Hz})$ \\
\hline 1 & 173.8 & - & $1^{\prime}$ & 64.4 & $4.03(\mathrm{t}, 6.7)$ \\
\hline 2 & 34.5 & $2.26(\mathrm{t}, 6.7)$ & $2^{\prime}$ & 28.7 & $1.59(\mathrm{~m})$ \\
\hline 3 & 25.1 & $1.59(\mathrm{~m})$ & $3^{\prime}$ & 26.0 & $1.22(\mathrm{~m})$ \\
\hline 4 & 29.2 & $1.23(\mathrm{~m})$ & $4^{\prime}$ & 29.3 & $1.23-1.29(\mathrm{~m})$ \\
\hline 5 & 29.3 & $1.23-1.29(\mathrm{~m})$ & $5^{\prime}$ & 29.43 & $1.23-1.29(\mathrm{~m})$ \\
\hline 6 & 29.43 & $1.23-1.29(\mathrm{~m})$ & $6^{\prime}$ & 29.72 & $1.23-1.29(\mathrm{~m})$ \\
\hline 7 & 29.72 & $1.23-1.29(\mathrm{~m})$ & $7^{\prime}$ & 29.76 & $1.23-1.29(\mathrm{~m})$ \\
\hline 8 & 29.76 & $1.23-1.29(\mathrm{~m})$ & $8^{\prime}$ & 29.76 & $1.23-1.29(\mathrm{~m})$ \\
\hline 9 & 29.76 & $1.23-1.29$ & $9^{\prime}$ & 29.76 & $1.23-1.29(\mathrm{~m})$ \\
\hline 10 & 29.76 & $1.23-1.29(\mathrm{~m})$ & $10^{\prime}$ & 29.72 & $1.23-1.29(\mathrm{~m})$ \\
\hline 11 & 29.72 & $1.23-1.29(\mathrm{~m})$ & $11^{\prime}$ & 29.72 & $1.23-1.29(\mathrm{~m})$ \\
\hline 12 & 29.72 & $1.23-1.29(\mathrm{~m})$ & $12^{\prime}$ & 29.67 & $1.23-1.29(\mathrm{~m})$ \\
\hline 13 & 29.67 & $1.23-1.29(\mathrm{~m})$ & $13^{\prime}$ & 29.64 & $1.23-1.29(\mathrm{~m})$ \\
\hline 14 & 29.64 & $1.23-1.29(\mathrm{~m})$ & $14^{\prime}$ & 29.76 & $1.23-1.29(\mathrm{~m})$ \\
\hline 15 & 29.76 & $1.23-1.29(\mathrm{~m})$ & $15^{\prime}$ & 29.76 & $1.23-1.29(\mathrm{~m})$ \\
\hline 16 & 29.76 & $1.23-1.29(\mathrm{~m})$ & $16^{\prime}$ & 29.72 & $1.23-1.29(\mathrm{~m})$ \\
\hline 17 & 29.59 & $1.23-1.29(\mathrm{~m})$ & $17^{\prime}$ & 29.64 & $1.23-1.29(\mathrm{~m})$ \\
\hline 18 & 29.54 & $1.23-1.29(\mathrm{~m})$ & $18^{\prime}$ & 29.59 & $1.23-1.29(\mathrm{~m})$ \\
\hline 19 & 29.43 & $1.23-1.29(\mathrm{~m})$ & $19^{\prime}$ & 29.54 & $1.23-1.29(\mathrm{~m})$ \\
\hline 20 & 32.0 & $1.23-1.29(\mathrm{~m})$ & $20^{\prime}$ & 29.43 & $1.23-1.29(\mathrm{~m})$ \\
\hline 21 & 22.8 & $1.27(\mathrm{~m})$ & $21^{\prime}$ & 32.0 & $1.23-1.29(\mathrm{~m})$ \\
\hline \multirow[t]{2}{*}{22} & 14.2 & $0.88(\mathrm{t}, 6.7)$ & $22^{\prime}$ & 22.8 & $1.27(\mathrm{~m})$ \\
\hline & & & $23^{\prime}$ & 14.2 & $0.88 \mathrm{t}, 6.7)$ \\
\hline
\end{tabular}

\subsection{Biological activities.}

Antimicrobial activity testing of the crude extract of the soft coral Sarcophyton trocheliophorum and compounds 1-4 was carried out against Staphylococcus aureus, Bacillus subtilis ATCC6051, Streptomyces viridochromogenes Tü 57, Escherichia coli, Mucor miehei Tü 284, Candida albicans, and the green alga Chlorella vulgaris. The crude extract exhibited a moderate activity against Streptomyces viridochromogenes Tü $57(12 \mathrm{~mm})$ at a concentration of $400 \mu \mathrm{g} / \mathrm{disc}$, meanwhile, the reported compounds $\mathbf{1 - 4}$ showed no activity against the reported test microorganisms at a concentration of $40 \mu \mathrm{g} / \mathrm{disc}$. 


\section{Conclusions}

Three phenolic metabolites: 2,4-di-tert-butyl-6-nitrophenol (1), 2,4-di-tertbutyl-phenol (2), 2,4-bis(1-methyl-1-phenylethyl)-phenol (3) in addition to the wax tricosyldocosanoiate (4) were isolated from Sarcophyton trocheliophorum, collected from Red Sea. The antimicrobial activity of the crude extract and compounds 1-4 isolated from Sarcophyton trocheliophorum was carried out against Staphylococcus aureus, Bacillus subtilis ATCC6051, Streptomyces viridochromogenes Tü 57, Escherichia coli, Mucor miehei Tü 284, Candida albicans, and the green alga Chlorella vulgaris. The crude extract exhibited a moderate activity against Streptomyces viridochromogenes Tü $57(12 \mathrm{~mm}$ ) at a concentration of $400 \mu \mathrm{g} / \mathrm{disc}$, whereas the reported compounds $\mathbf{1 - 4}$ showed no activity against the reported test microorganisms at a concentration of $40 \mu \mathrm{g} / \mathrm{disc}$.

\section{Funding}

This research received no external funding.

\section{Acknowledgments}

The authors are deeply thankful to Prof. H. Laatsch, Institute of Organic and Biomolecular Chemistry, Göttingen, for his support and lab facilities. We thank Dr. H. Frauendorf and Dr. M. John for the mass and NMR spectra. The authors would like to acknowledge Ms. F. Lissy for biological activity tests. M. Shaaban thanks the German Academic Exchange Service (DAAD) for a short-term grant.

\section{Conflicts of Interest}

The authors reported no potential conflict of interest.

\section{Supplementary material}

NMR and mass spectra of compounds 1-4 are provided.

\section{References}

1. Helber, S.B.; Hoeijmakers, D.J.J.; Muhando, C.A.; Rohde S., Schupp P.J. Sponge chemical defenses are a possible mechanism for increasing sponge abundance on reefs in Zanzibar. PLoS ONE 2018, 13(6): e0197617. https://doi.org/10.1371/journal.pone.0197617.

2. Rodrigues, I.G.; Miguel, M.G.; Mnif, W. A Brief Review on New Naturally Occurring Cembranoid Diterpene Derivatives from the Soft Corals of the Genera Sarcophyton, Sinularia, and Lobophytum Since 2016. Molecules 2019. 24(4), 781. https://doi.org/10.3390/

3. Farag, M.A.; Porzel, A.; Al-Hammady, M.A.; Hegazy, M.E.F.; Meyer, A.; Mohamed, T.A.; Westphal, H.; Wessjohann, L.A. Soft corals biodiversity in the Egyptian Red Sea: a comparative MS and NMR metabolomics approach of wild and aquarium grown species. Journal of proteome research 2016, 15(4), pp.1274-1287.

4. Elkhawas, Y.A.; Elissawy, A.M.; Elnaggar, M.S.; Mostafa, N.M.; Al-Sayed, E.; Bishr, M.M.; Singab, A.N.B.; Salama, O.M. Chemical Diversity in Species Belonging to Soft Coral Genus Sacrophyton and Its Impact on Biological Activity: A Review. Marine Drugs 2020, 18, 41. https://doi.org/10.3390/md18010041.

5. Kasimala, M.; Babu, B. H.; Awet, B. A.; Henok, G. G.; Haile, A. H.; Hisham, O. M. A review on bioactive secondary metabolites of soft corals (Octocorallia) and their distribution in Eritrean coast of Red Sea. Indian Journal of Geo-Marine Sciences 2020, 49, 1793-1800. 
6. Shaaban, M.; Ghani, M.A.; Shaaban, K.A. Unusual pyranosyl cembranoid diterpene from Sarcophyton trocheliophorum. Zeitschrift für Naturforschung B 2016, 71, 1211-1217, https://doi.org/10.1515/znb-20160144.

7. Shaaban, K.A.; Ghani, M.A.; Shaaban, M. New Cembranoid Diterpenes from Sarcophyton trocheliophorum. Journal of Pharmaceutical Research International 2015, 5, 192-201, https://doi.org/10.9734/BJPR/2015/14757.

8. Shaaban, M.; Shaaban, K.A.; Ghani, M.A. Hurgadacin: A new steroid from Sinularia polydactyla. Steroids 2013, 78, 866-873, https://doi.org/10.1016/j.steroids.2013.05.006.

9. Shaaban, M.; Shaaban, K.A.; Abd-Alla, H.I.; Hanna, A.G.; Laatsch, H. Dendrophen, a novel glycyrrhetyl amino acid from Dendronephthya hemprichi. Zeitschrift für Naturforschung B 2011, 66, 425-432, https://doi.org/10.1515/znb-2011-0413.

10. Shaaban, M.; Ghani, M.A.; Shaaban, K.A. Zahramycins A-B, two new steroids from the coral Sarcophyton trocheliophorum. Zeitschrift für Naturforschung B 2013, 68, 939-945, https://doi.org/10.5560/ZNB.20133131.

11. Shaaban, M.; El-Hagrassi, A.M.; Abdelghani, M.A.; Osman, A.F. Diverse bioactive compounds from Sarcophtyton glaucom: structure elucidation and cytotoxic activity studies. Zeitschrift für Naturforschung C 2017, 73, 325-334, https://doi.org/10.1515/znc-2017-0106.

12. Shaaban, M.; Issa, M.Y.; Ghani, M.A.; Hamed, A.; Abdelwahab, A.B. New pyranosyl cembranoid diterpenes from Sarcophyton trocheliophorum. Natural Product Research 2019, 33, 24-33, https://doi.org/10.1080/14786419.2018.1431631.

13. Shaheen, H.A.; Issa, M.Y. In vitro and in vivo activity of Peganum harmala L. alkaloids against phytopathogenic bacteria. Scientia Horticulturae $\quad \mathbf{2 0 2 0}$., $\quad 264, \quad 108940$. https://doi.org/10.1016/j.scienta.2019.108940.

14. Ernest Vončina; Križanec, B., Organic compounds in drinking waters during use of plastic water pipes in Slovenian Chemical Days 2008 2008, Maribor: University of Maribor, Faculty of Chemistry and Chemical Technology: Maribor, Slovenia.

15. Schopfer, M.P.; Mondal, B.; Lee, D.-H.; Sarjeant, A.A.; Karlin, K.D. Heme/O2/• NO nitric oxide dioxygenase (NOD) reactivity: phenolic nitration via a putative heme-peroxynitrite intermediate. Journal of the American Chemical Society 2009, 131, 11304-11305, https://doi.org/10.1021/ja904832j.

16. Cross, G.G.; Fischer, A.; Henderson, G.N. ipso Nitration. XXV. Nitration of di-tert-butylphenols, $\alpha$-(3, 5-ditert-butylphenoxy) isobutyric acid, and 3,5-di-tert-butylphenoxyacetic acid: formation of nitrodienones and nitrodienes containing a secondary nitro group. Can. J. Chem. 1984, 62, 2803-2812.

17. Liu, Z.-h.; Yin, H.; Dang, Z. Do estrogenic compounds in drinking water migrating from plastic pipe distribution system pose adverse effects to human? An analysis of scientific literature. Environmental Science and Pollution Research 2017, 24, 2126-2134, https://doi.org/10.1007/s11356-016-8032-z.

18. Zeng, X. Comparative analysis of volatile constituents in herbal pair Flos Lonicerae-radix Glycyrrhizae and its single herbs. Guangzhou Huagong 2014, 42, 99-102.

19. KANG, X.-1.; LIU, X.; LUO, J.-r. Analysis of Fat-soluble Constituents in Pine Cone of Pinus yunnanensis from Various Habitats by GC-MS. Chinese Journal of Experimental Traditional Medical Formulae 2014, $12,031$.

20. Wei, Y.-1.; Yang, M.-f.; Liu, A.-y. Analysis of composition and content of fatty acids in Cordyceps cicadae Shing. Shipin Gongye Keji 2014, 35, 303-305, 318.

21. Yong;, C.; Hou-chao;, W.; Li, N. Analysis of Volatile Oil in Abutilon indicum (L. ) Sweet from Various Habitats by GC-MS. Global Traditional Chinese Medicine 2013, 6, 572-575.

22. Yan, L.; He-dong, H.; Hai-qing, H.; Rong-jiao, L.; Yan, L.; Xiao-ling, W. Analysis on Fat-soluble Constituents in Flowers of Tibetan Medicinal Plants of Three Gentiana Species by GC-MS Chinese Journal of Experimental Traditional Medical Formulae 2013, 19, 102-107.

23. Rana, V.S.; Blazquez, M.A. Chemical constituents of Gynura cusimbua aerial parts. J Essent Oil Res 2007, 19, 21-22, https://doi.org/10.1080/10412905.2007.9699219.

24. Hua, H.; Li, X.; Xing, S.; Pei, Y. Chemical constituents of Linaria vulgaris. Zhongguo Yaoxue Zazhi 2005, 40, 653-656.

25. Chee, S.Y.K.; Malek, S.N.A.; Ramli, N. Essential Oils in the Leaves of Cocoa (Theobroma cacao L.) Clone UITI and NA33. J Essent Oil Res 2005, 17, 312-313, https://doi.org/10.1080/10412905.2005.9698914. 
26. Johnson, J.; Citarasu, T.; Manjusha, W. Antimicrobial screening and identification of bioactive compounds present in marine sponge Zygomycale sp. collected from Kanyakumari coast. J. chem. biol. phys. sci. 2012, 2, 1842-1848.

27. Ozdemir, G.; Horzum, Z.; Sukatar, A.; Karabay-Yavasoglu, N.U. Antimicrobial activities of volatile components and various extracts of Dictyopteris membranaceae. and Cystoseira barbata. from the coast of Izmir, Turkey. Pharmaceutical biology 2006, 44, 183-188, https://doi.org/10.1080/13880200600685949.

28. Grigoriadou, A.; Schwarzbauer, J.; Georgakopoulos, A. Molecular indicators for pollution source identification in marine and terrestrial water of the industrial area of Kavala city, North Greece. Environ. Pollut. 2008, 151, 231-242, https://doi.org/10.1016/j.envpol.2007.01.053.

29. Dharni, S.; Maurya, A.; Samad, A.; Srivastava, S.K.; Sharma, A.; Patra, D.D. Purification, characterization, and in vitro activity of 2, 4-di-tert-butylphenol from Pseudomonas monteilii PsF84: conformational and molecular docking studies. J. Agric. Food. Chem. 2014, 62, 6138-6146, https://doi.org/10.1021/jf5001138.

30. Ma, X.; Wang, J.; Tian, Z.; Kang, Q.; Xu, Y. Study on toxicity of 2,4-di-tert-butylphenol to activated sludge microbes. Gongye Shuichuli 2015, 35, 18-21.

31. Belghit, S.; Driche, E.; Bijani, C.; Zitouni, A.; Sabaou, N.; Badji, B.; Mathieu, F. Activity of 2, 4-Di-tertbutylphenol produced by a strain of Streptomyces mutabilis isolated from a Saharan soil against Candida albicans and other pathogenic fungi. J. med. mycol. 2016, 26, 160-169, https://doi.org/10.1016/j.mycmed.2016.03.001.

32. Hua, Y.; Wang, H.-q. Chemical constituents of Seriphidium terrae-albae (Krasch) Poljak essential oils and their antibacterial activity. Zhongchengyao 2007, 29, 754-756.

33. Lee, Y.-S.; Chang, Z.-Q.; Oh, B.-C.; Park, S.-C.; Shin, S.-R.; Kim, N.-W. Antioxidant activity, antiinflammatory activity, and whitening effects of extracts of Elaeagnus multiflora Thunb. Journal of medicinal food 2007, 10, 126-133, https://doi.org/10.1089/jmf.2006.145.

34. Yoon, M.-A.; Jeong, T.-S.; Park, D.-S.; Xu, M.-Z.; Oh, H.-W.; Song, K.-B.; Lee, W.S.; Park, H.-Y. Antioxidant effects of quinoline alkaloids and 2, 4-di-tert-butylphenol isolated from Scolopendra subspinipes. Biological and Pharmaceutical Bulletin 2006, 29, 735-739, https://doi.org/10.1248/bpb.29.735.

35. Varsha, K.K.; Devendra, L.; Shilpa, G.; Priya, S.; Pandey, A.; Nampoothiri, K.M. 2, 4-Di-tert-butyl phenol as the antifungal, antioxidant bioactive purified from a newly isolated Lactococcus sp. International journal of food microbiology 2015, 211, 44-50, https://doi.org/10.1016/j.ijfoodmicro.2015.06.025.

36. Kang, C.-A.; Shin, S.-W. Studies on Compositions and Antifungal Activities of Essential Oils from Cultivars of Brassica juncea L. Korean J. Pharmacogn. 2001, 32, 140-144.

37. Malek, S.N.A.; Shin, S.K.; Wahab, N.A.; Yaacob, H. Cytotoxic components of Pereskia bleo (Kunth) DC.(Cactaceae) leaves. Molecules 2009, 14, 1713-1724, https://doi.org/10.3390/molecules14051713.

38. Zeng, Q.; Guan, B.; Cheng, X.; Wang, C.; Jin, H.-Z.; Zhang, W.-D. Chemical constituents from Metasequoia glyptostroboides $\mathrm{Hu}$ et Cheng. Biochemical Systematics and Ecology 2013, 50, 406-410, https://doi.org/10.1016/j.bse.2013.06.004.

39. Deng, M.-q.; Zhang, X.-p.; Wang, Q.; Yu, H.; Jiang, J.-h. Composition and biological activity of volatile oil from Dioscorea hypoglauca Palibin. Zhongguo Shiyan Fangjixue Zazhi 2008, 14, 6-8.

40. Dembitsky, V.M.; Rezanka, T. Molecular species of wax esters in Cereus peruvianus. Phytochemistry 1996, 42, 1075-1080, https://doi.org/10.1016/0031-9422(96)00048-9.

41. Arrendale, R.; Severson, R.; Chortyk, O.; Stephenson, M. Isolation and identification of the wax esters from the cuticular waxes of green tobacco leaf. Contrib. Tob. Res. 1988. 14, 67-84, https://doi.org/10.2478/cttr2013-0587.

42. Imbs, A.B.; Dang, L.P.; Rybin, V.G.; Nguyen, N.T.; Pham, L.Q. Distribution of very-long-chain fatty acids between molecular species of different phospholipid classes of two soft corals. Biochem. Anal. Biochem 2015, 4, 205, https://doi.org/10.4172/2161-1009.1000205.

43. Matsubara, T.; Morita, M.; Hayashi, A. Determination of the presence of ceramide aminoethylphosphonate and ceramide $\mathrm{N}$-methylaminoethylphosphonate in marine animals by fast atom bombardment mass spectrometry. Biochimica et Biophysica Acta (BBA)-Lipids and Lipid Metabolism 1990, 1042, 280-286, https://doi.org/10.1016/0005-2760(90)90154-P. 
Supplementary materials

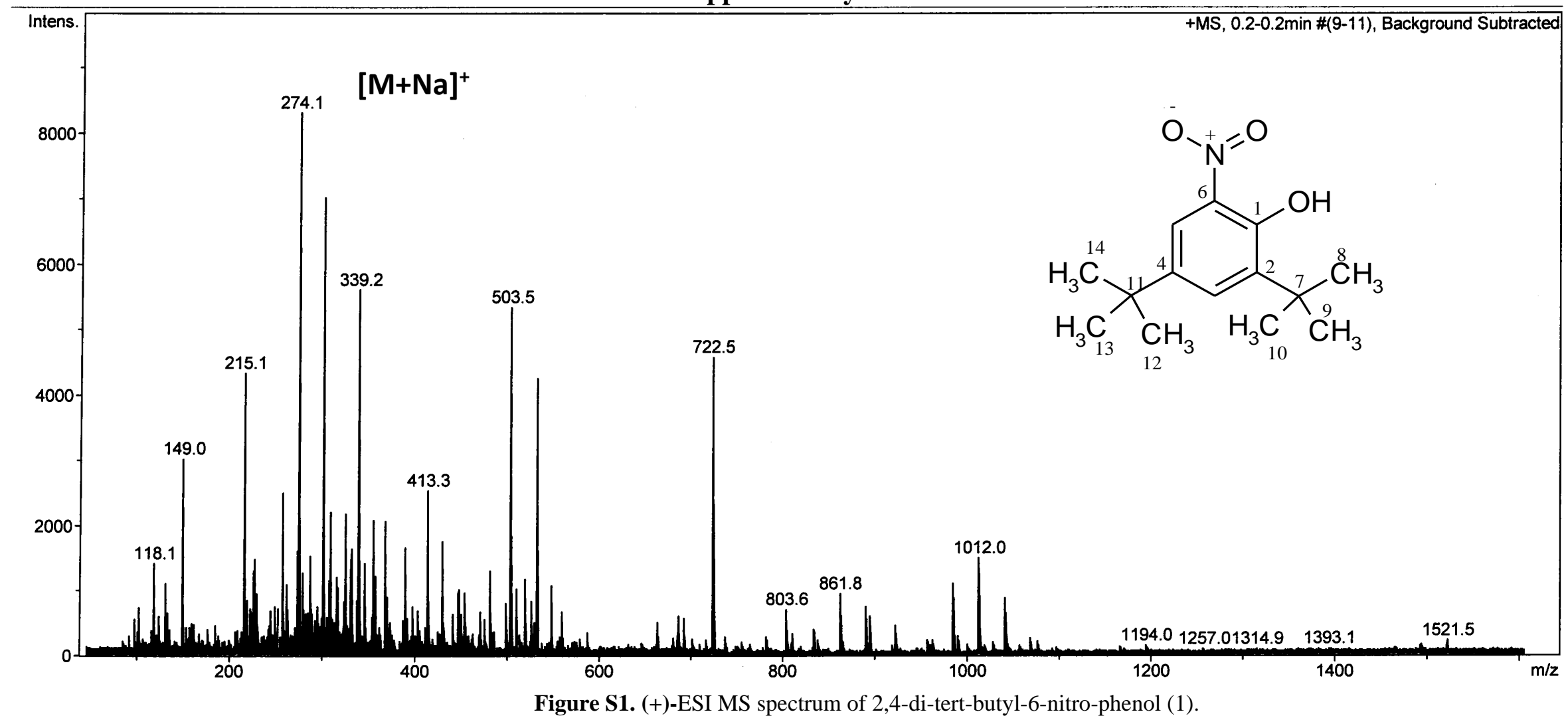

Figure S1. (+)-ESI MS spectrum of 2,4-di-tert-butyl-6-nitro-phenol (1). 


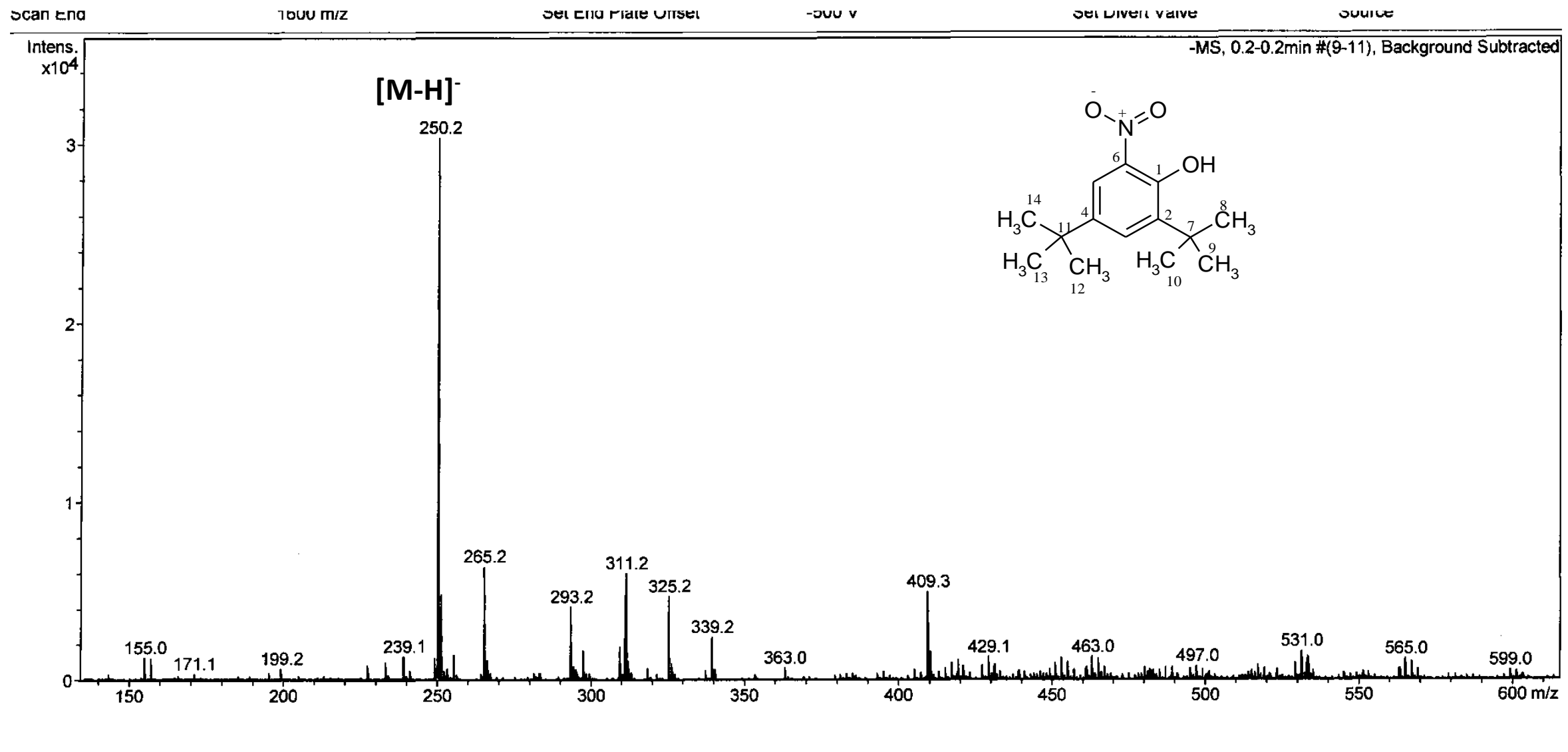

Bruker Compass DataAnalysis $\overline{4.0}$

printed:

11.12.2015 08:52:27

Page 1 of 1

Figure S2. (+)-ESI MS spectrum of 2,4-di-tert-butyl-6-nitro-phenol (1). 


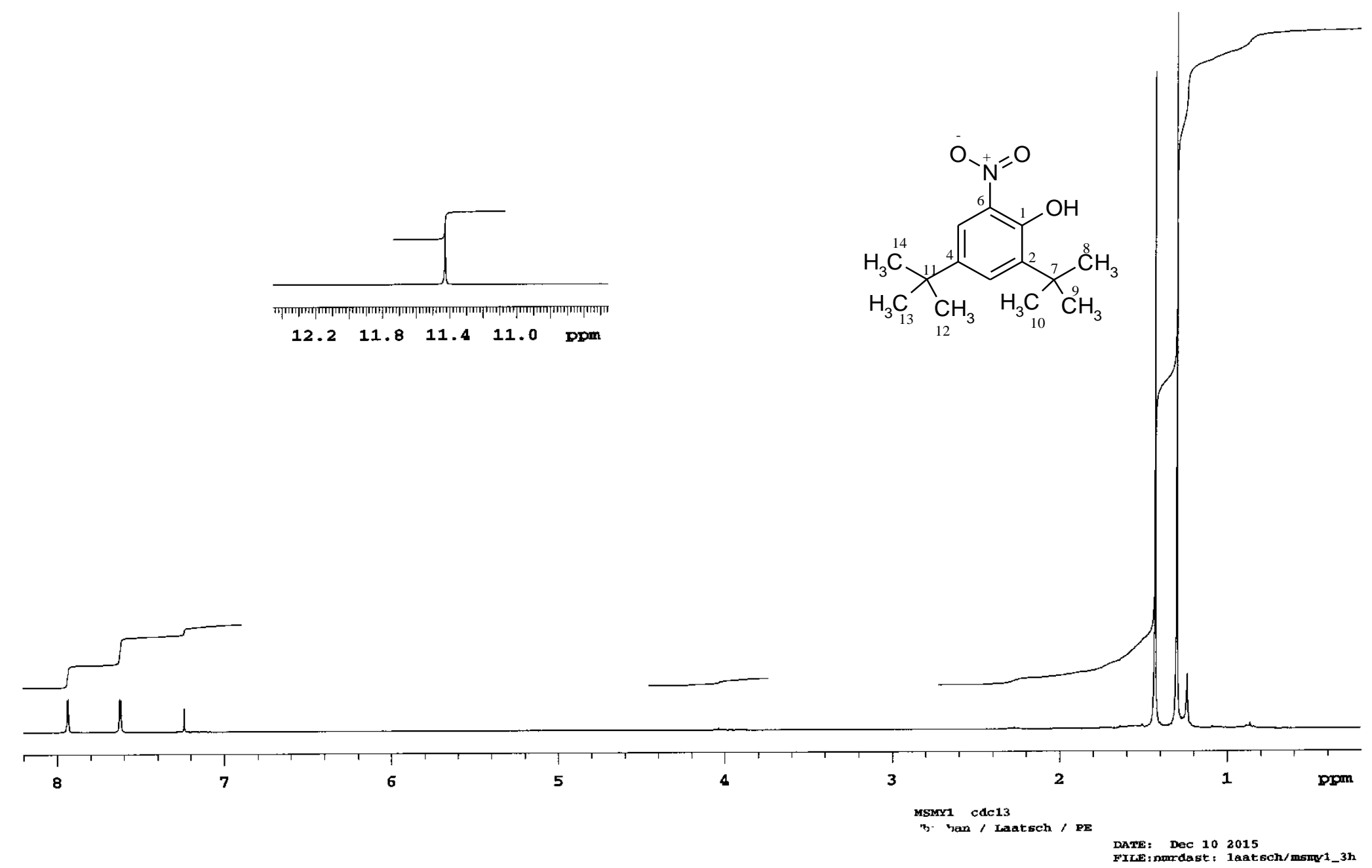

Figure S3. ${ }^{1} \mathrm{H}$ NMR spectrum $\left(\mathrm{CDCl}_{3}, 300 \mathrm{MHz}\right)$ of 2,4-di-tert-butyl-6-nitro-phenol (1). 


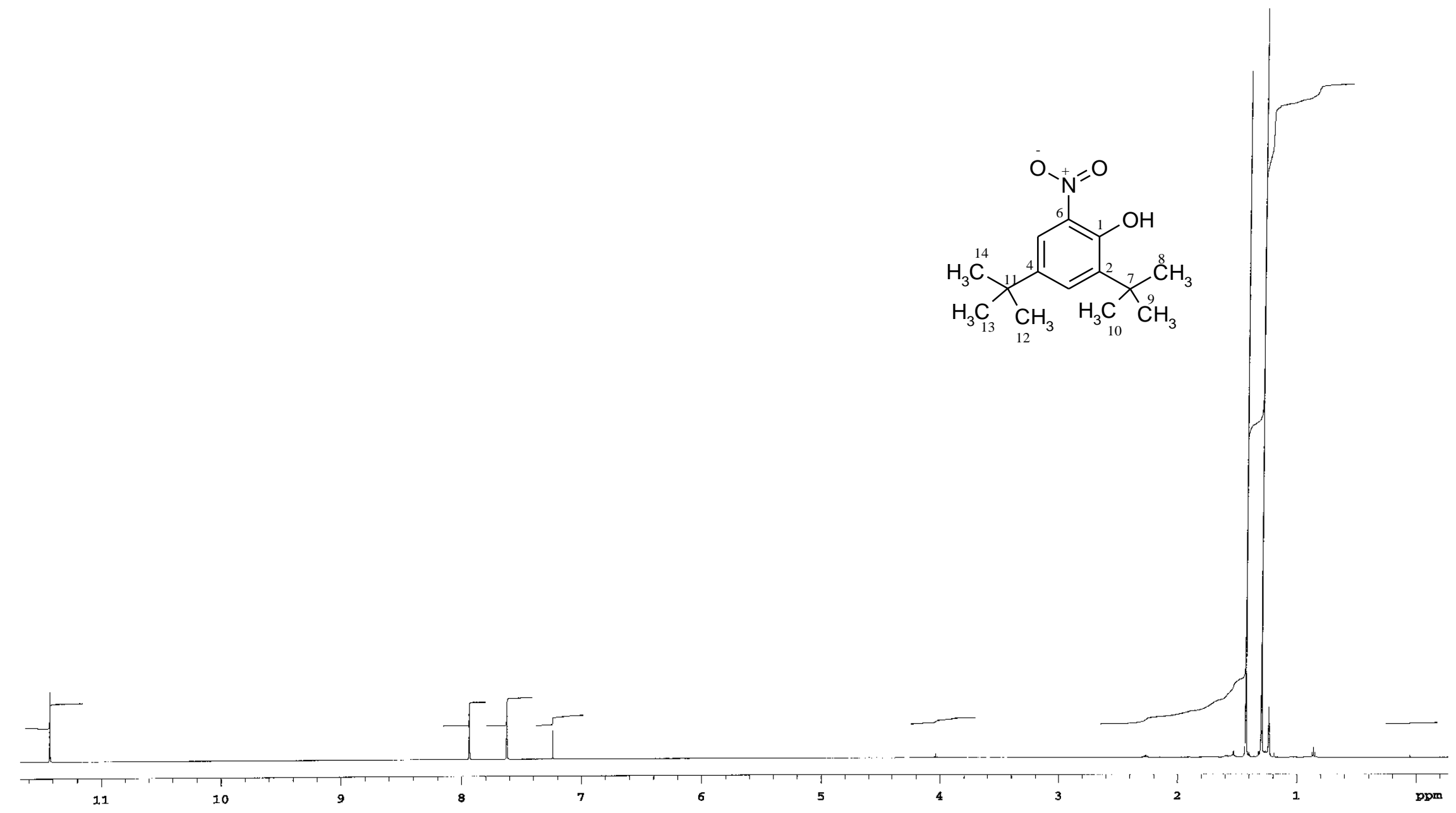

Figure S4. ${ }^{1} \mathrm{H}$ NMR spectrum $\left(\mathrm{CDCl}_{3}, 600 \mathrm{MHz}\right)$ of 2,4-di-tert-butyl-6-nitro-phenol (1). 

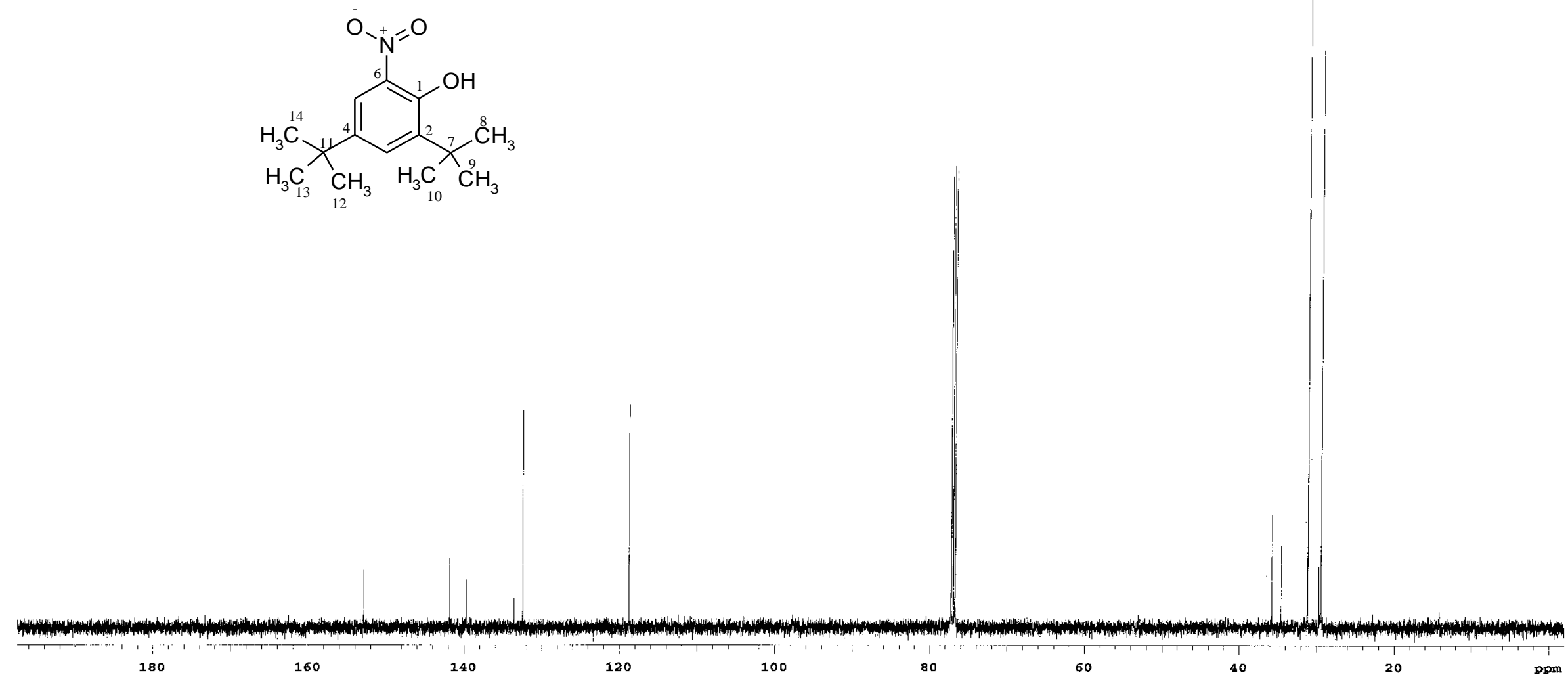

Figure S5. ${ }^{13} \mathrm{C}$ NMR spectrum $\left(\mathrm{CDCl}_{3}, 125 \mathrm{MHz}\right)$ of 2,4-di-tert-butyl-6-nitro-phenol (1). 


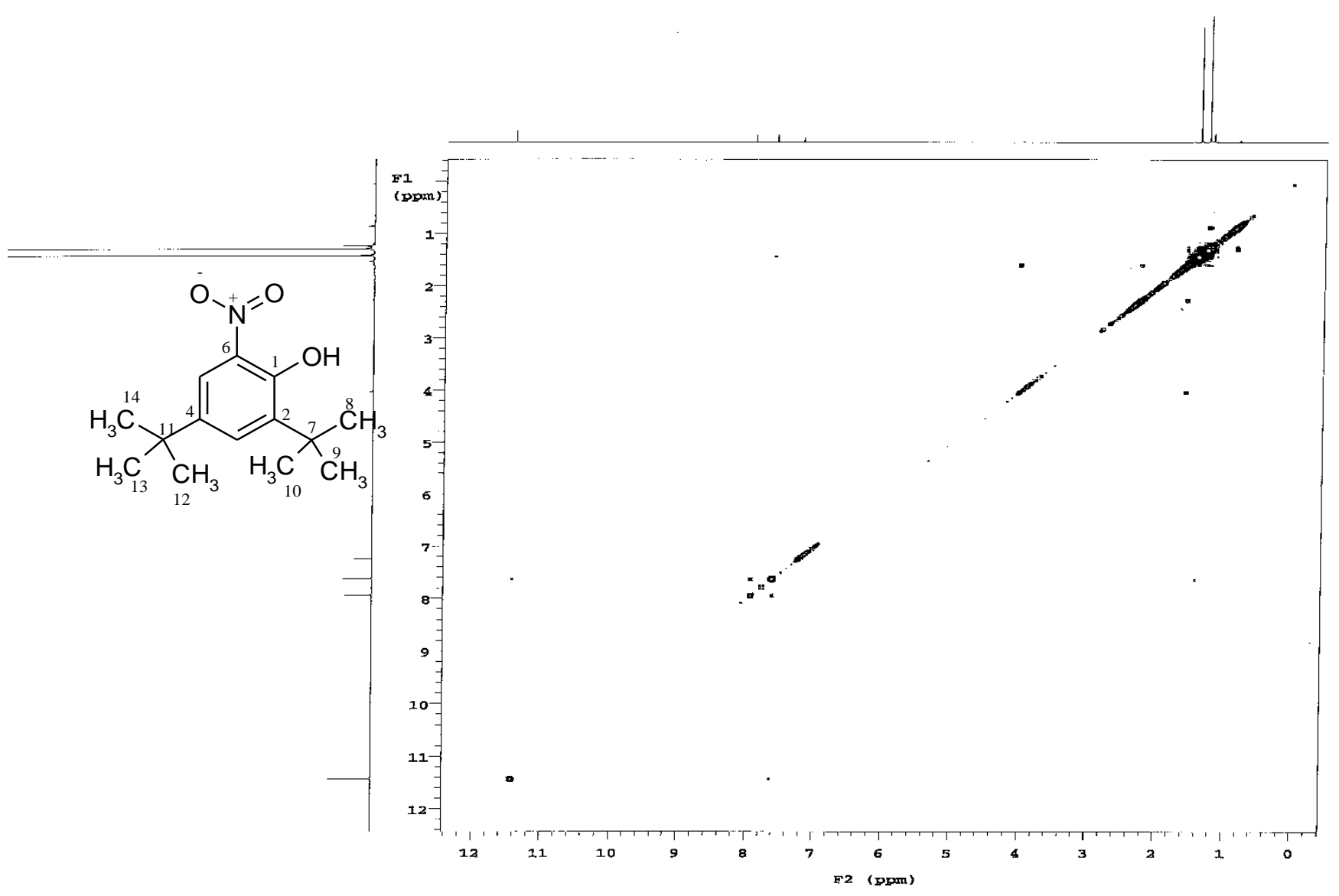

Figure S6. ${ }^{1} \mathrm{H}-{ }^{1} \mathrm{H}-\mathrm{COSY}$ spectrum $\left(\mathrm{CDCl}_{3}, 500 \mathrm{MHz}\right)$ of 2,4-di-tert-butyl-6-nitro-phenol (1). 


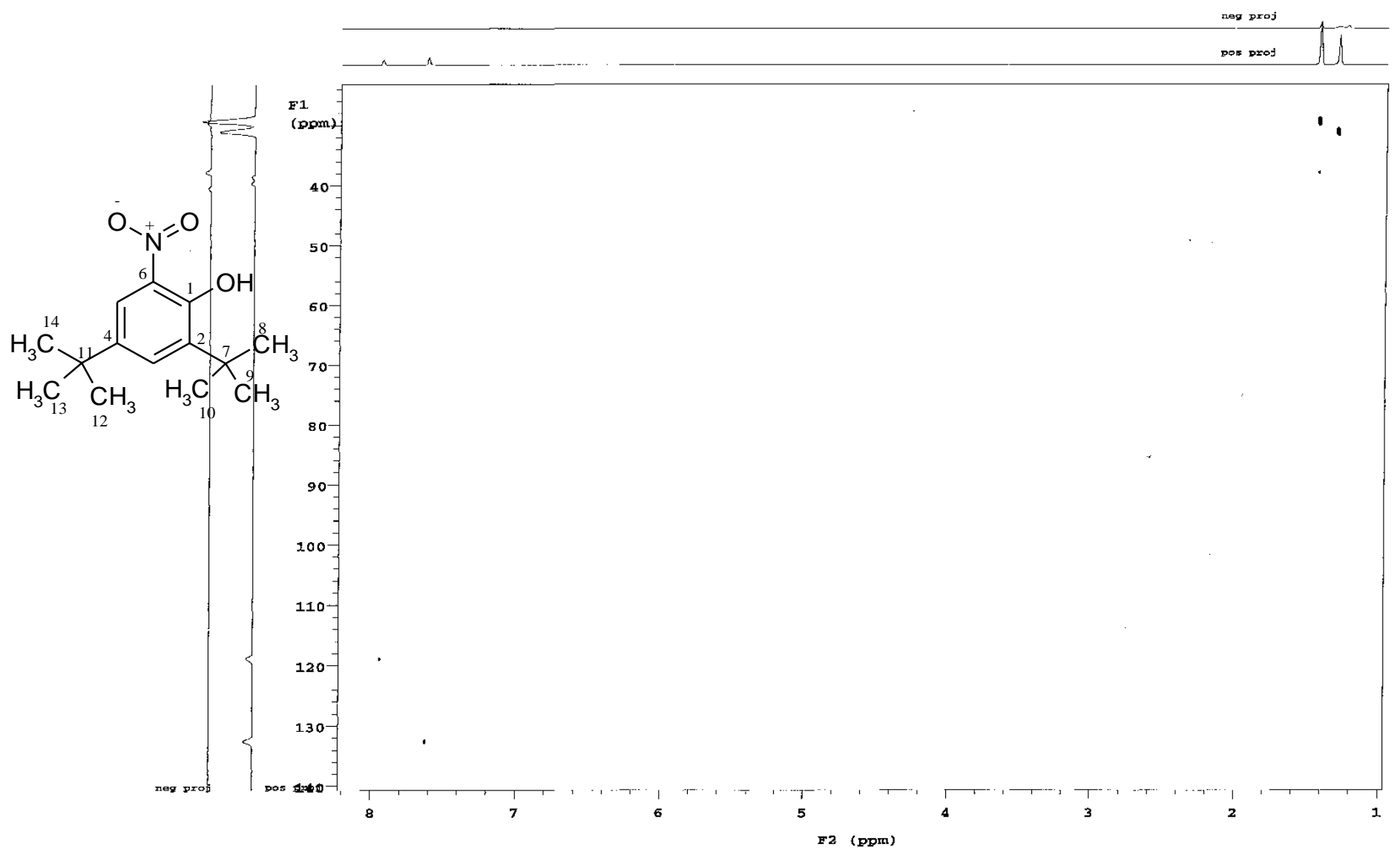

Figure S7. HSQC spectrum $\left(\mathrm{CDCl}_{3}, 500 \mathrm{MHz}\right)$ of 2,4-di-tert-butyl-6-nitro-phenol (1). 


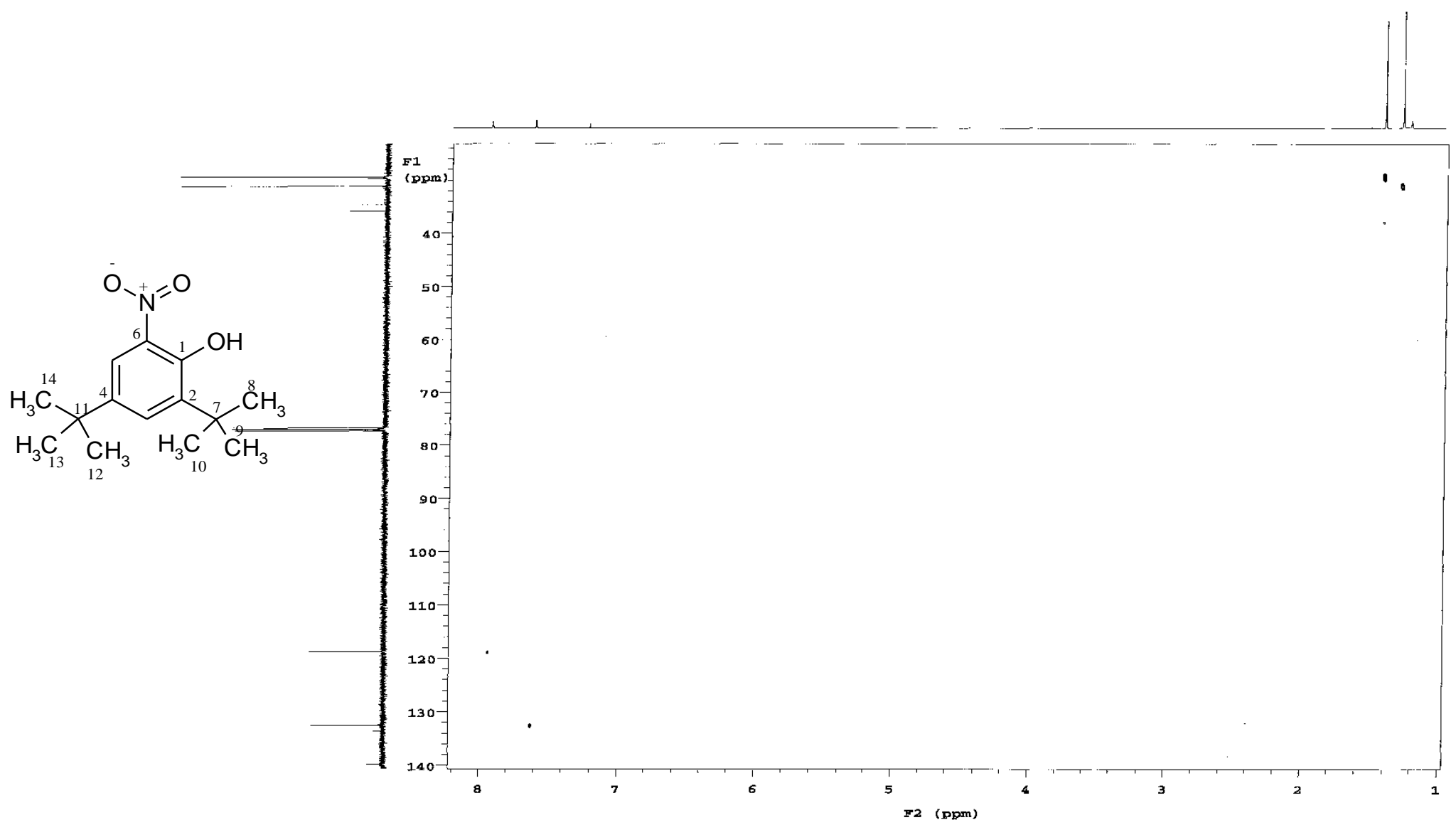

Figure S8. HMQC spectrum $\left(\mathrm{CDCl}_{3}, 500 \mathrm{MHz}\right)$ of 2,4-di-tert-butyl-6-nitro-phenol (1) 


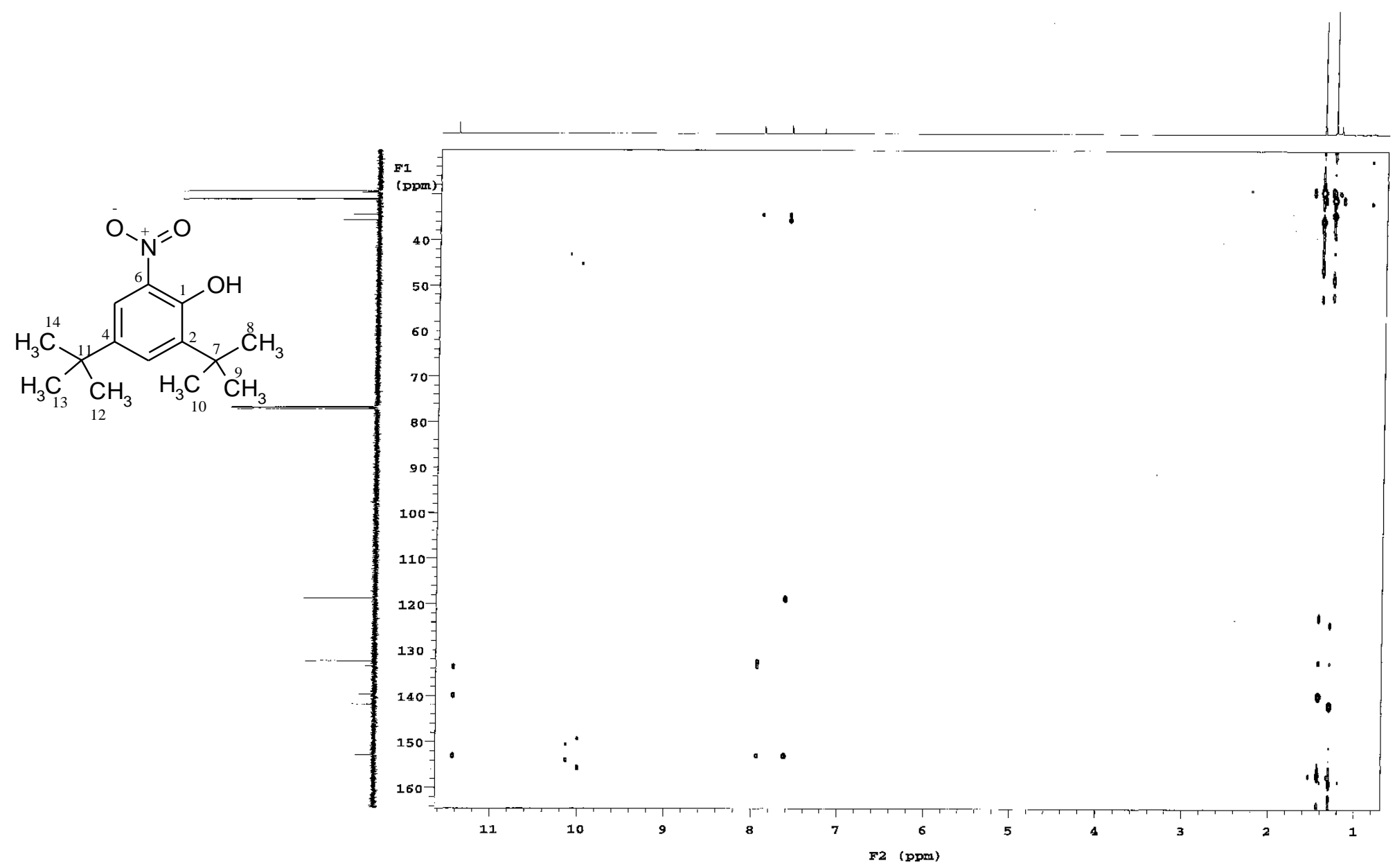

Figure S9. $\mathrm{HMBC}$ spectrum $\left(\mathrm{CDCl}_{3}, 500 \mathrm{MHz}\right)$ of 2,4-di-tert-butyl-6-nitro-phenol (1). 
Acq. Data Name: shaaban 151216-4

Acq. Data Name: shaaban $151216-4$
Creation Parameters: MS[1] Data Number: 1
Comment: Shaaban MSMY5

$$
\text { Relative Area }
$$

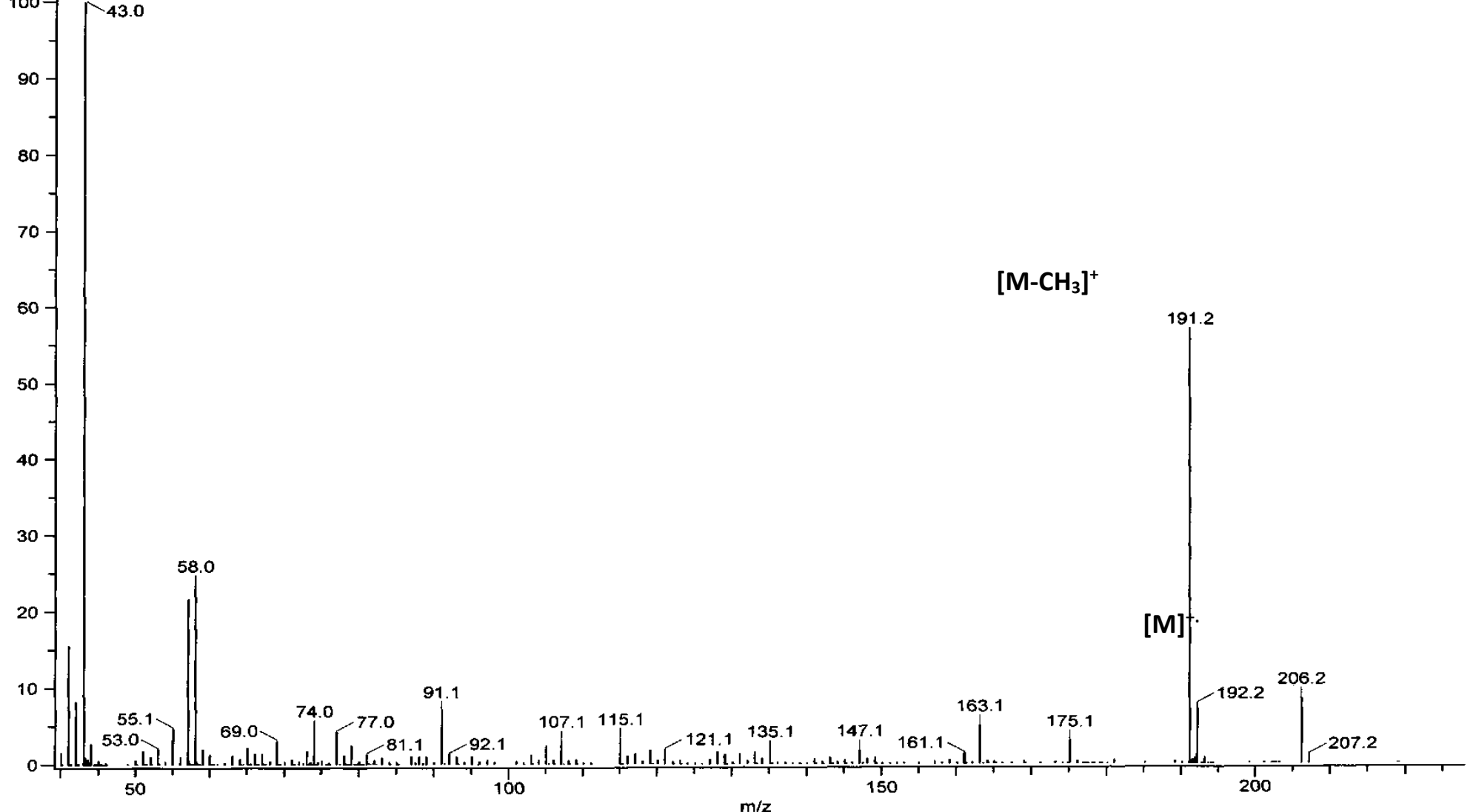

$\mathrm{m} / \mathbf{z}$ Experiment Date/Time: 12/16/2015 3:02:22 PM
lonization Mode: El+

Figure S10. EI MS of 2,4-di-tert-butyl-phenol (2). 


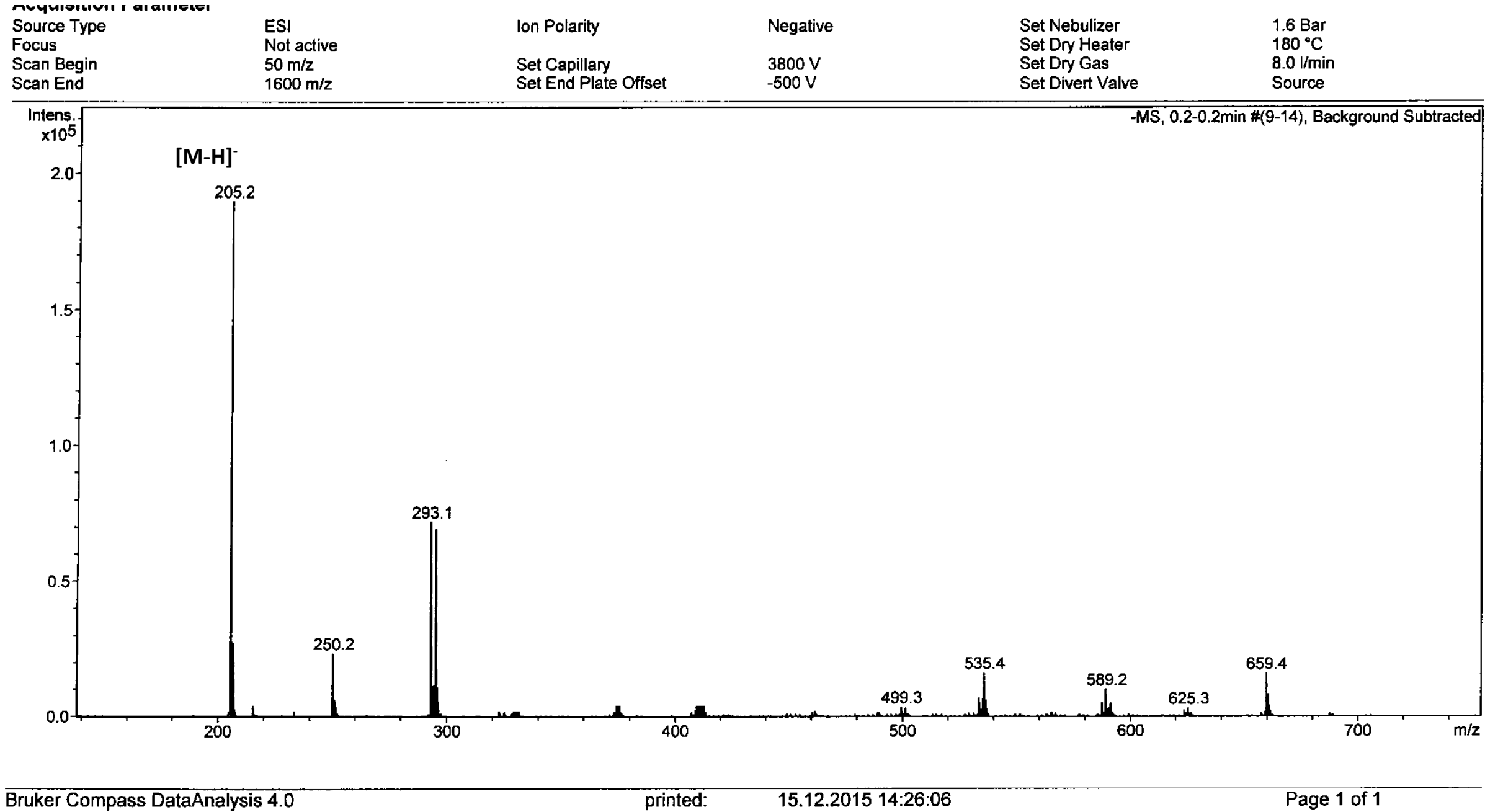

Figure S11. (-)-ESI MS of 2,4-di-tert-butyl-phenol (2). 


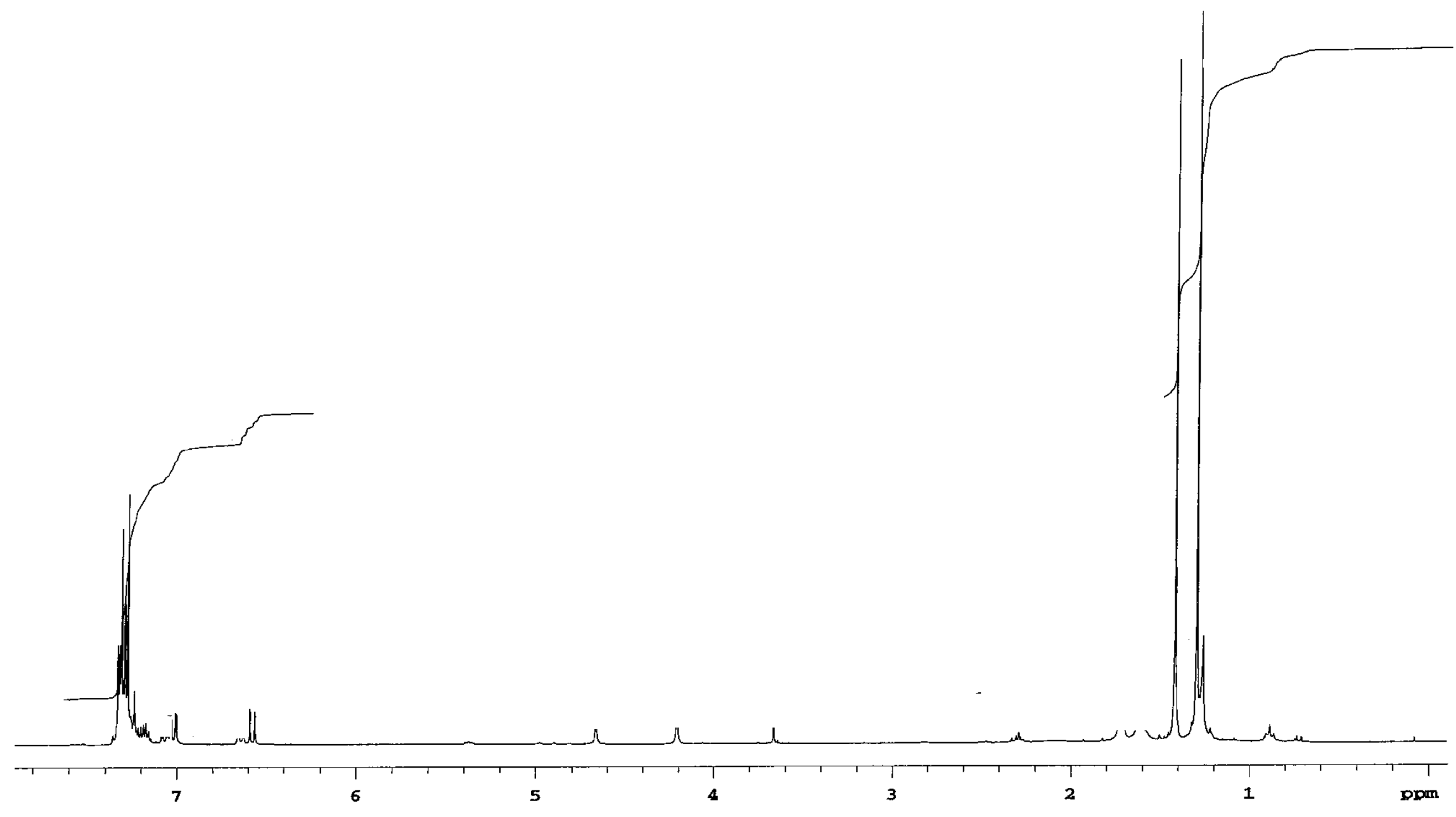

Figure S12. ${ }^{1} \mathrm{H}$ NMR spectrum $\left(\mathrm{CDCl}_{3}, 300 \mathrm{MHz}\right)$ of 2,4-di-tert-butyl-phenol (2). 


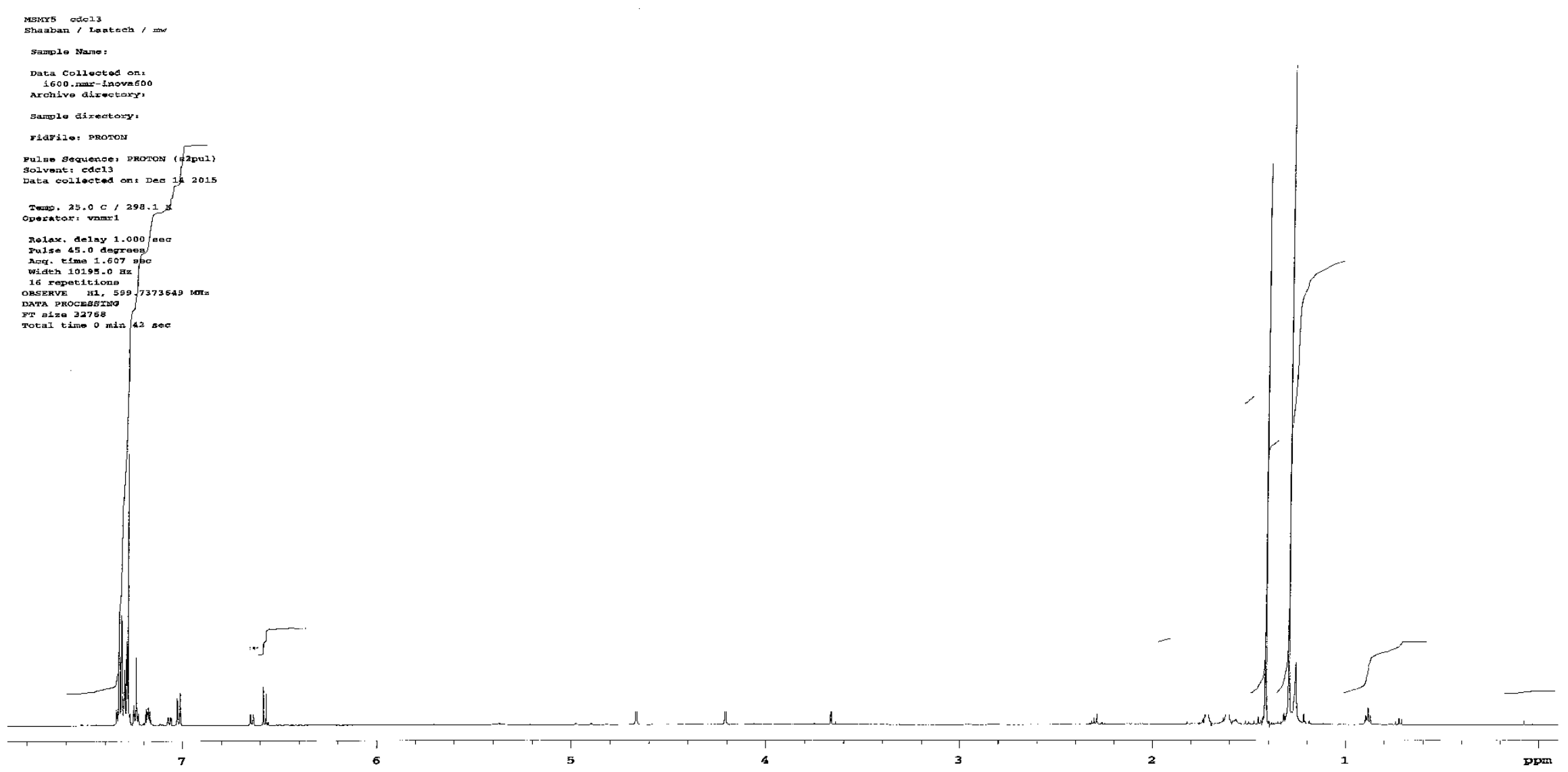

Figure S13. ${ }^{1} \mathrm{H}$ NMR spectrum $\left(\mathrm{CDCl}_{3}, 600 \mathrm{MHz}\right)$ of 2,4-di-tert-butyl-phenol (2). 


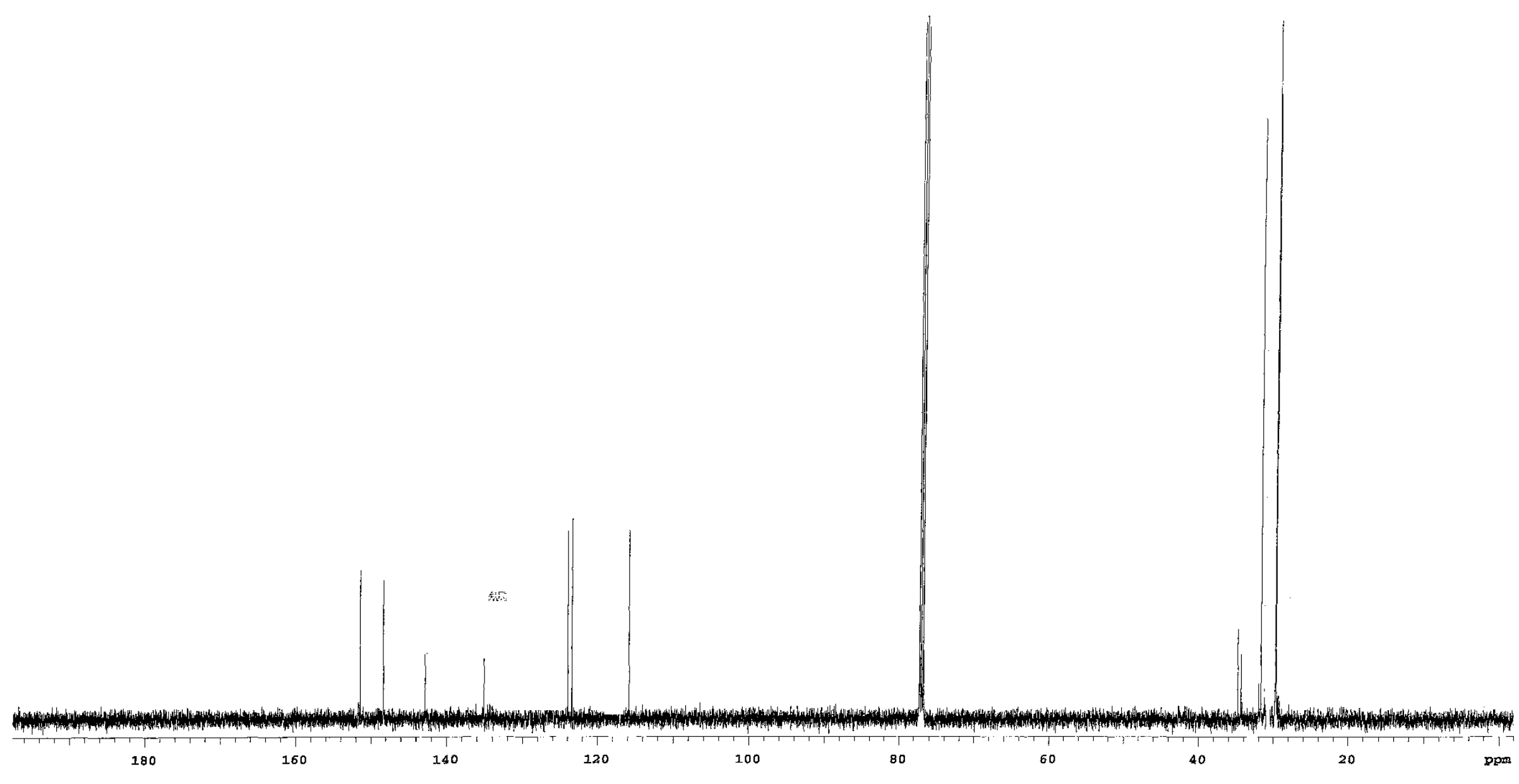

Figure S14. ${ }^{13} \mathrm{C}$ NMR spectrum ( $\mathrm{CDCl}_{3}, 125 \mathrm{MHz}$ ) of 2,4-di-tert-butyl-phenol (2). 


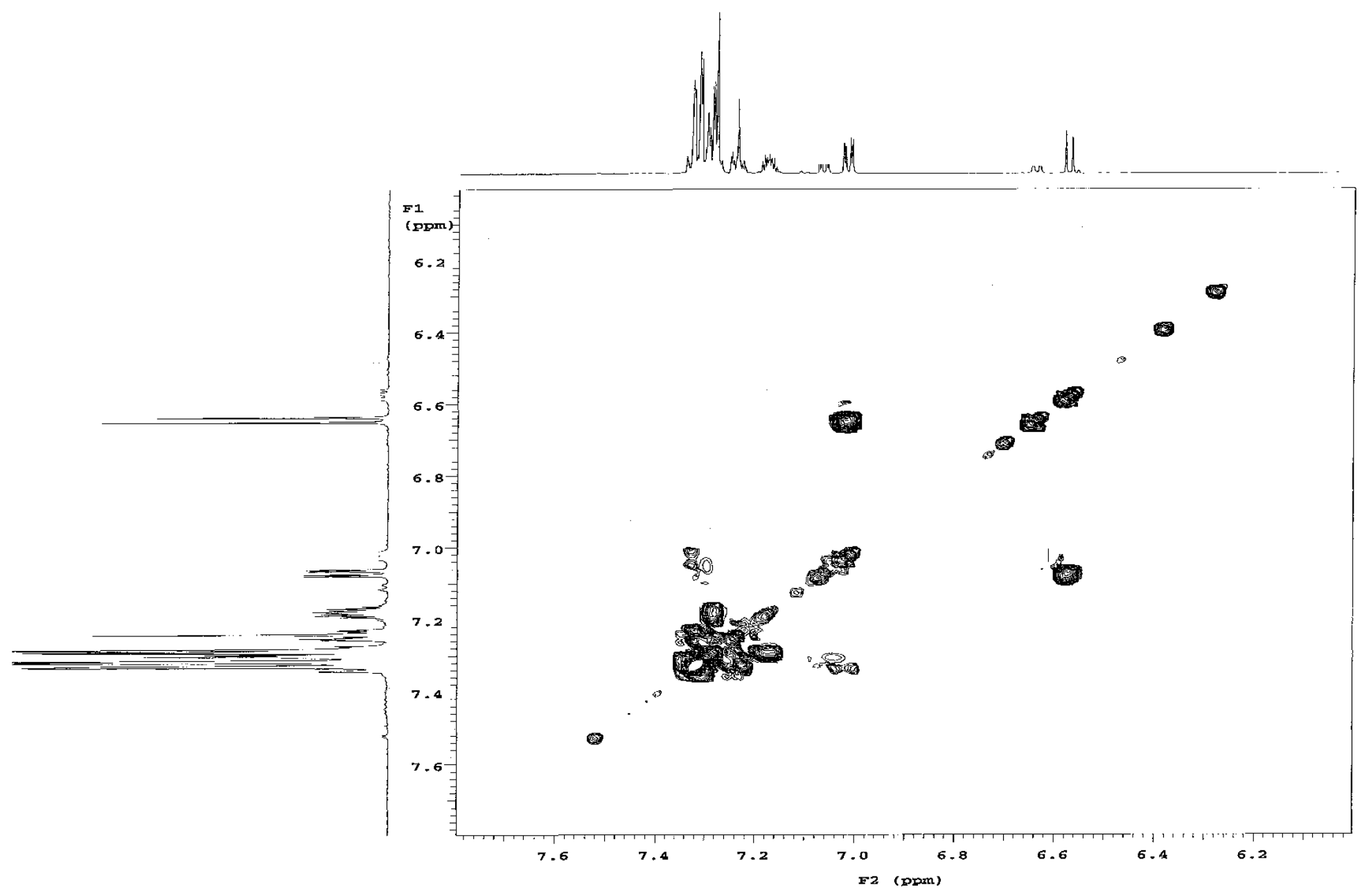

Figure S15. ${ }^{1} \mathrm{H}-\mathrm{H}$ COSY spectrum $\left(\mathrm{CDCl}_{3}, 500 \mathrm{MHz}\right)$ of 2,4-di-tert-butyl-phenol (2). 


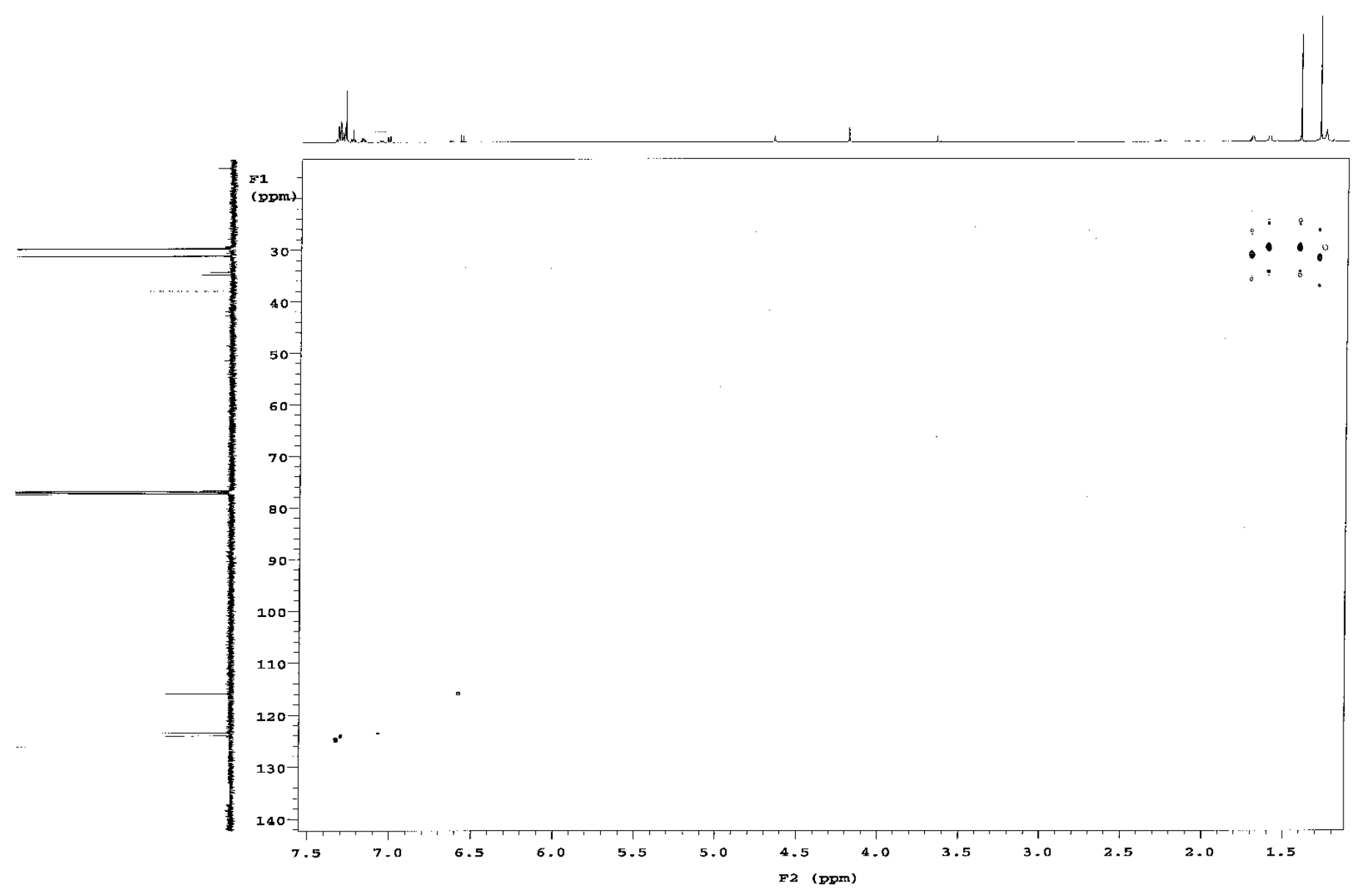

Figure S16. HMQC spectrum $\left(\mathrm{CDCl}_{3}, 500 \mathrm{MHz}\right)$ of 2,4-di-tert-butyl-phenol (2). 


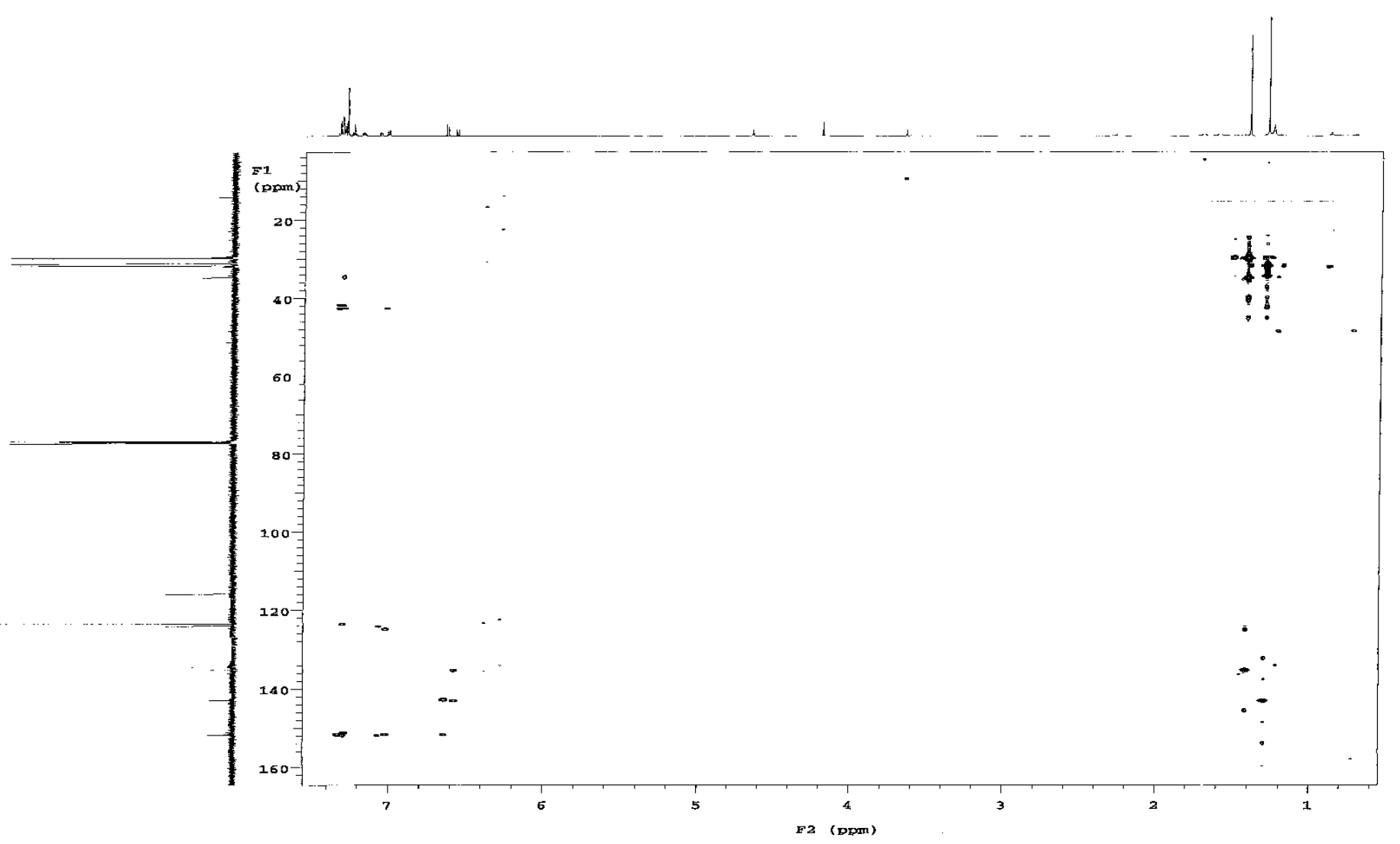

Figure S17. HMBC spectrum $\left(\mathrm{CDCl}_{3}, 500 \mathrm{MHz}\right)$ of 2,4-di-tert-butyl-phenol (2). 
Acq. Data Name: shaaban151216-4

Acq. Data Name: Shaaban 151216-4
Creation Parameters: Average(MS[1] Time:0.06.0.09)
Comment: Shaaban MSMY5

Relative Area

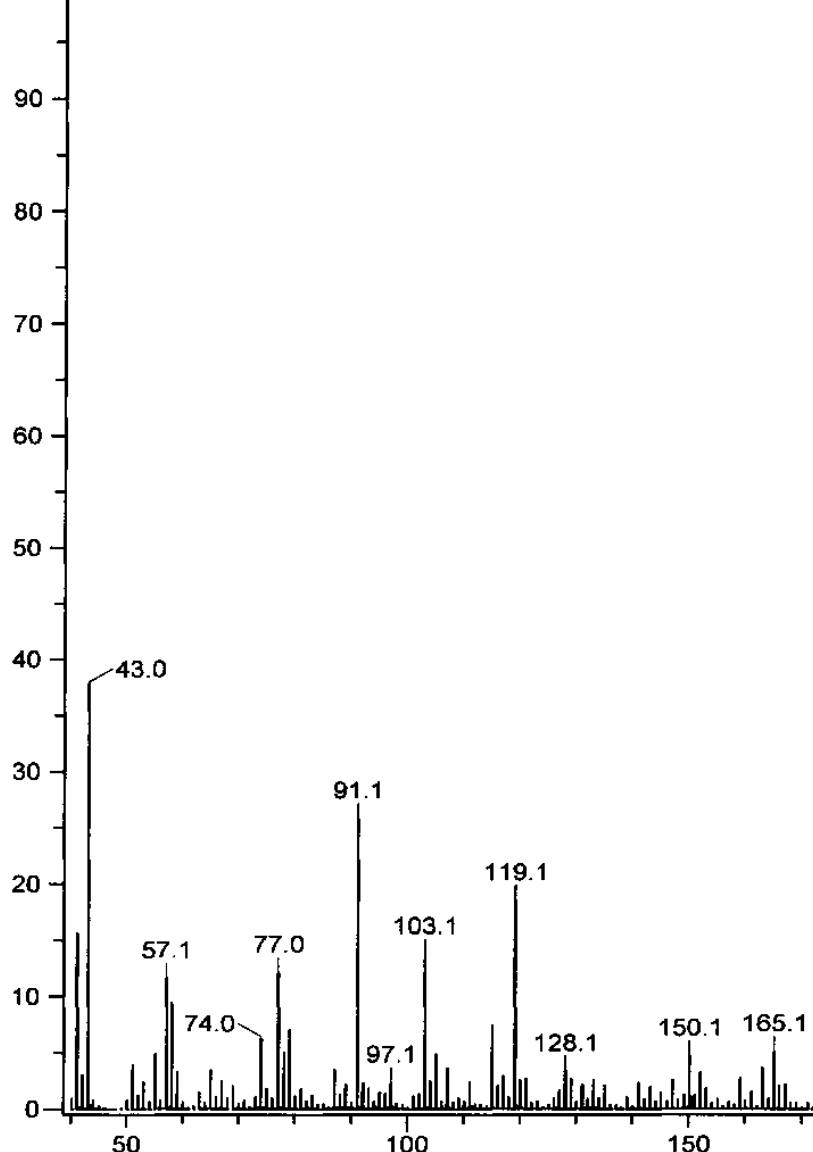

Experiment Date/Time: 12/16/2015 3.02.22 PM

$\left[\mathrm{M}-\mathrm{CH}_{3}\right]^{+}$ lonization Mode: $\mathrm{El+}$

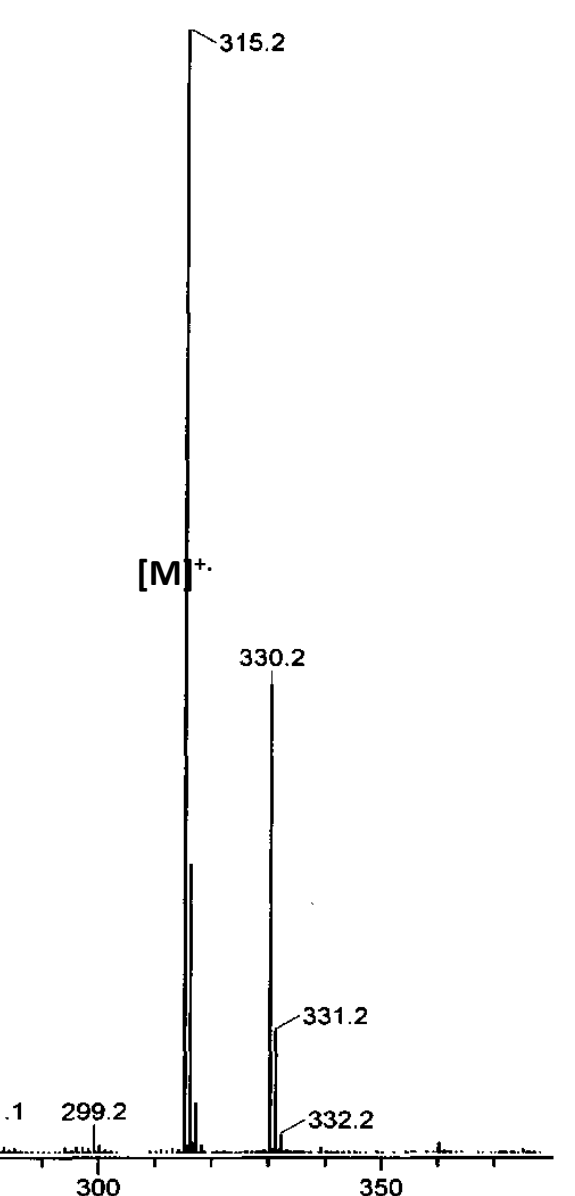

Figure S18. -EI MS spectrum of 2,4-bis(1-methyl-1-phenylethyl)-phenol (3). 
Hit 1 : Phenol, 2,4-bis(1-methyl-1-phenylethyl)-

C24H26O; MF: 854; RMF: 865; Prob 95.9\%; CAS: 2772-45-4; Lib: replib; ID: 27640

$100-$

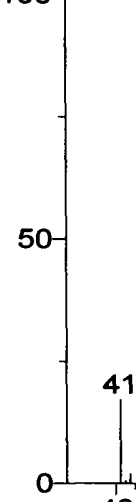

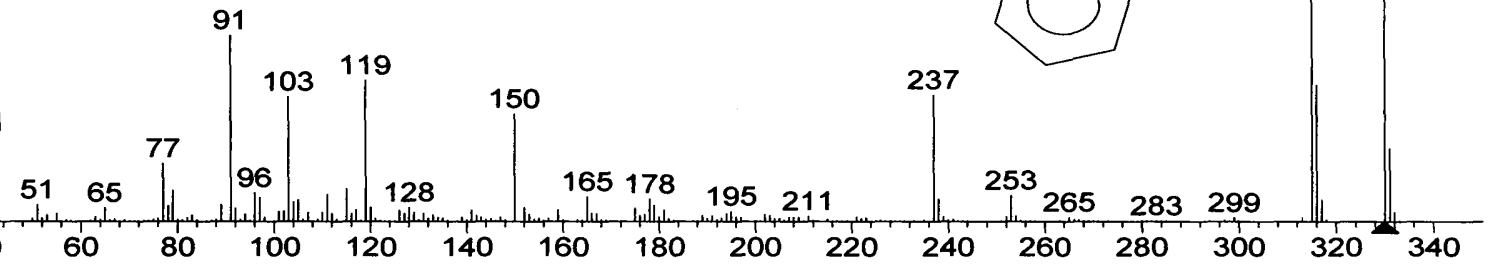

(replib) Phenol, 2,4-bis(1-methyl-1-phenylethyl)-

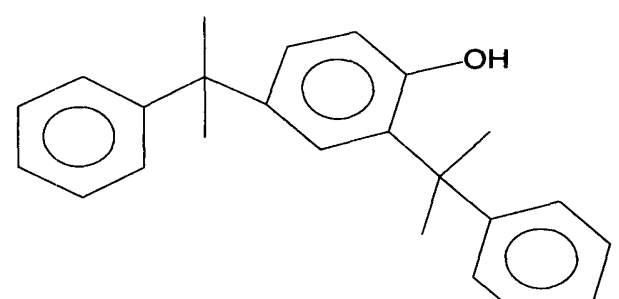

315

330

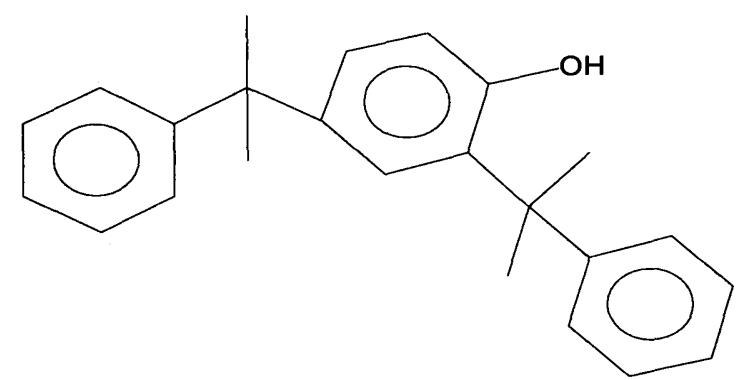

Figure S19. EI MS spectrum of 2,4-bis(1-methyl-1-phenylethyl)-phenol (3). 


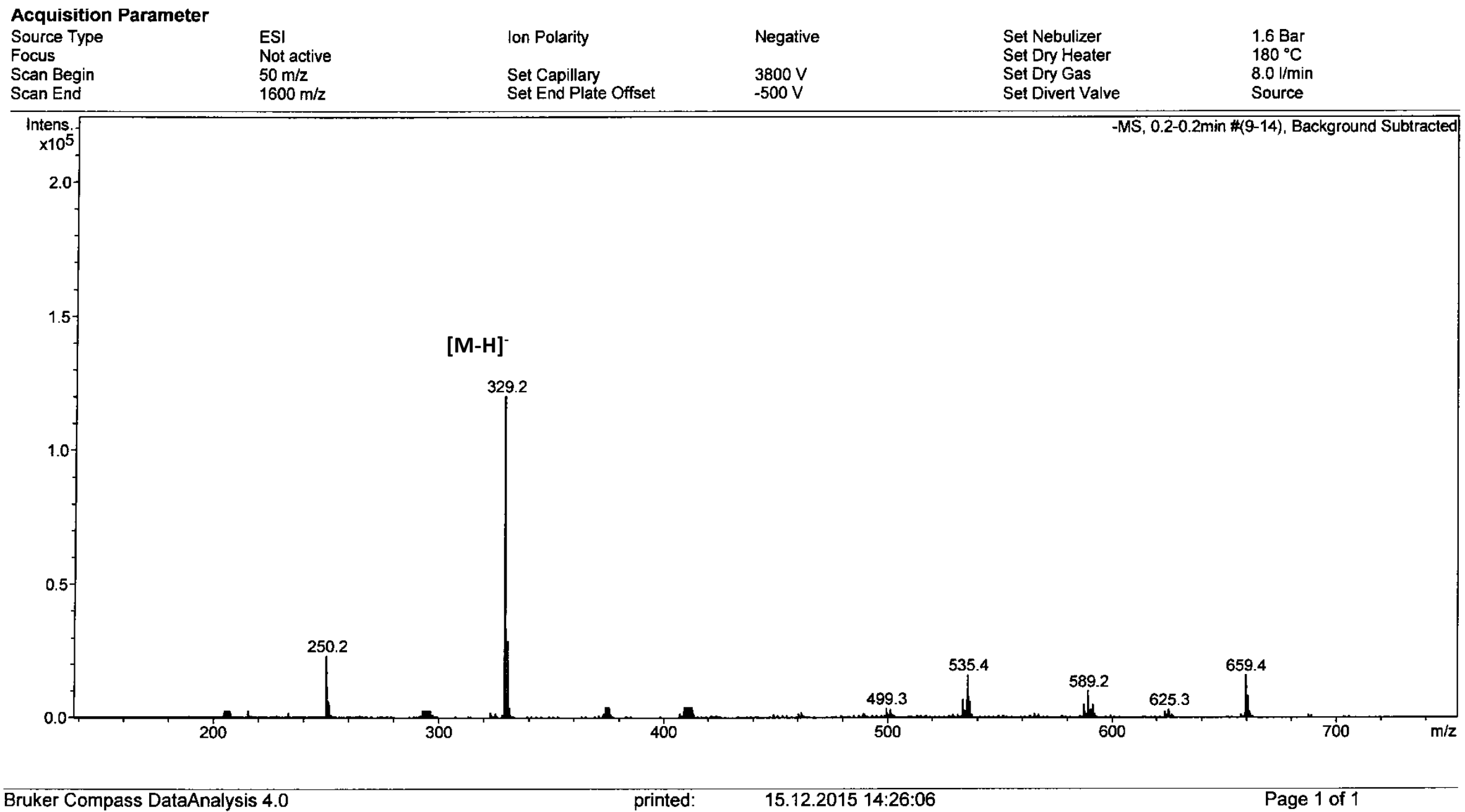

Figure S20. -(-)-ESI MS spectrum of 2,4-bis(1-methyl-1-phenylethyl)-phenol (3). 


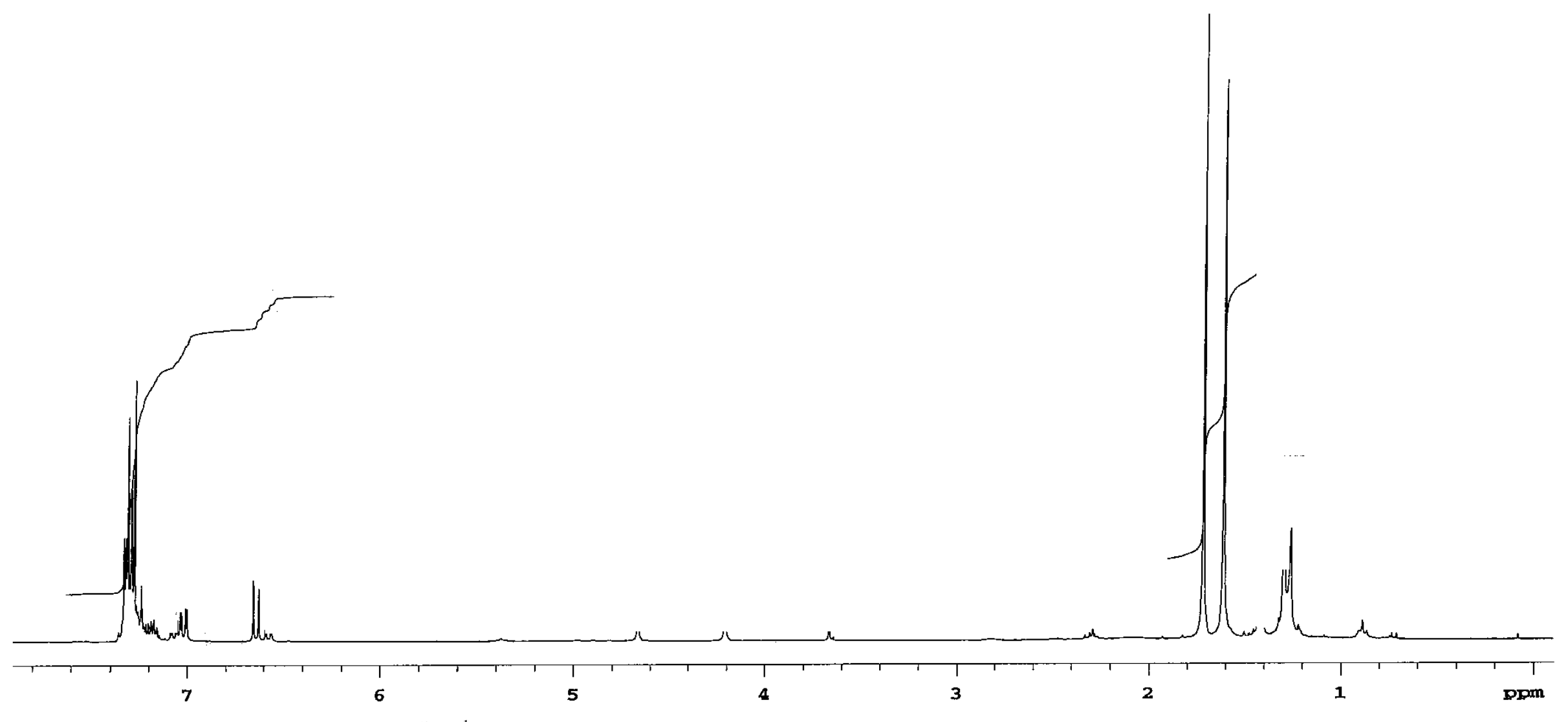

Figure S21. ${ }^{1} \mathrm{H}$ NMR spectrum ( $\left.\mathrm{CDCl}_{3}, 300 \mathrm{MHz}\right)$ of 2,4-bis(1-methyl-1-phenylethyl)-phenol (3). 


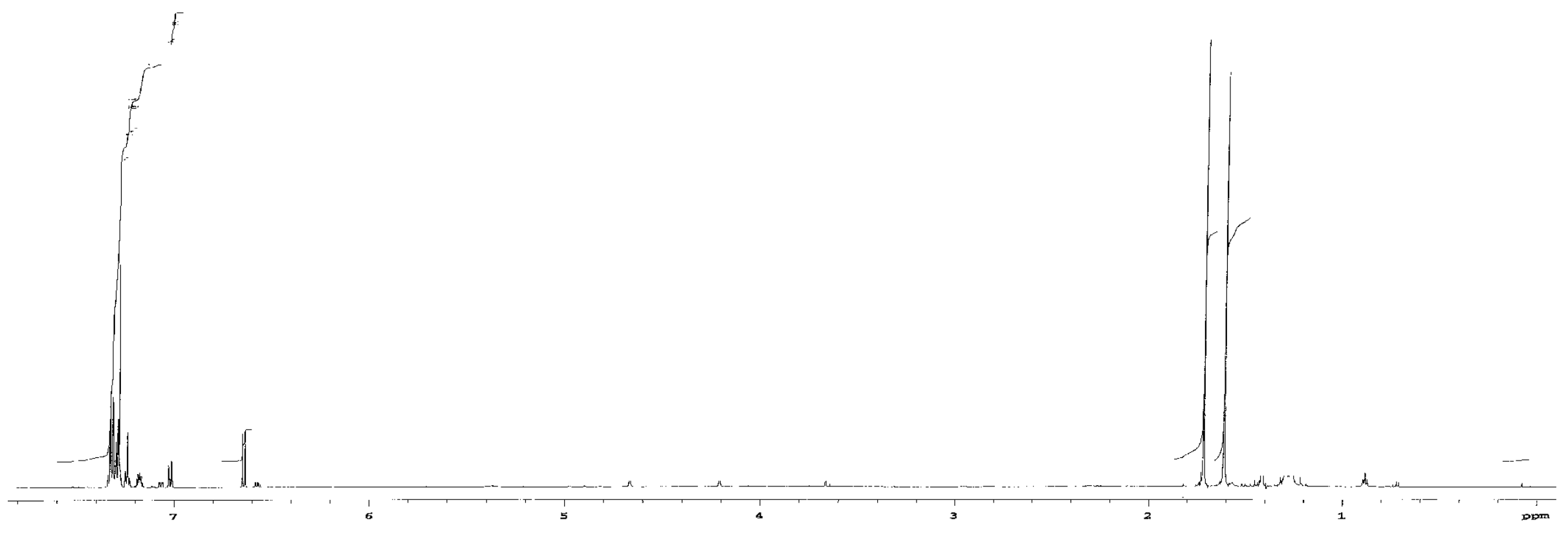

Figure S22. ${ }^{1} \mathrm{H}$ NMR spectrum $\left(\mathrm{CDCl}_{3}, 600 \mathrm{MHz}\right)$ of 2,4-bis(1-methyl-1-phenylethyl)-phenol (3). 


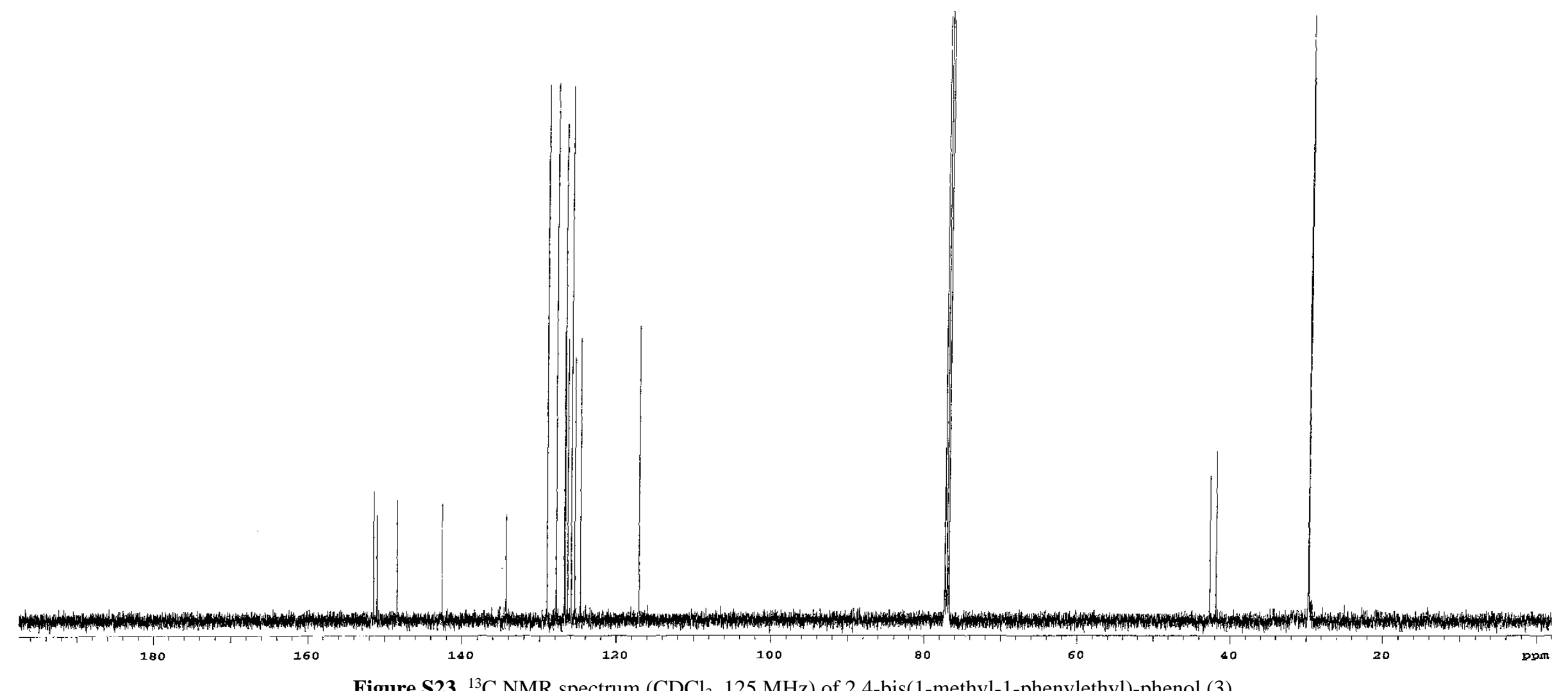

Figure S23. ${ }^{13} \mathrm{C}$ NMR spectrum ( $\mathrm{CDCl}_{3}, 125 \mathrm{MHz}$ ) of 2,4-bis(1-methyl-1-phenylethyl)-phenol (3). 


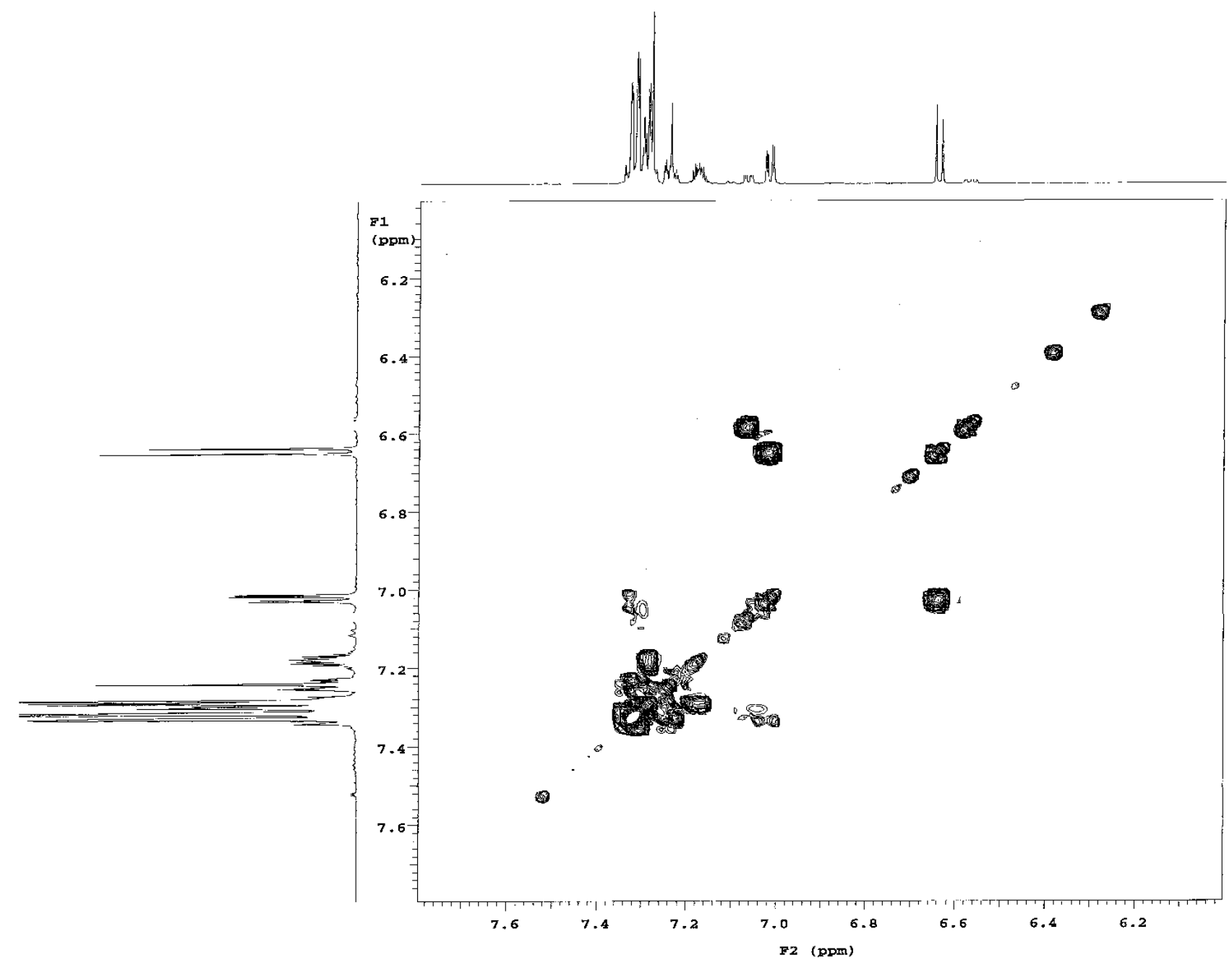

Figure S24. H,H COSY spectrum $\left(\mathrm{CDCl}_{3}, 500 \mathrm{MHz}\right)$ of 2,4-bis(1-methyl-1-phenylethyl)-phenol (3). 


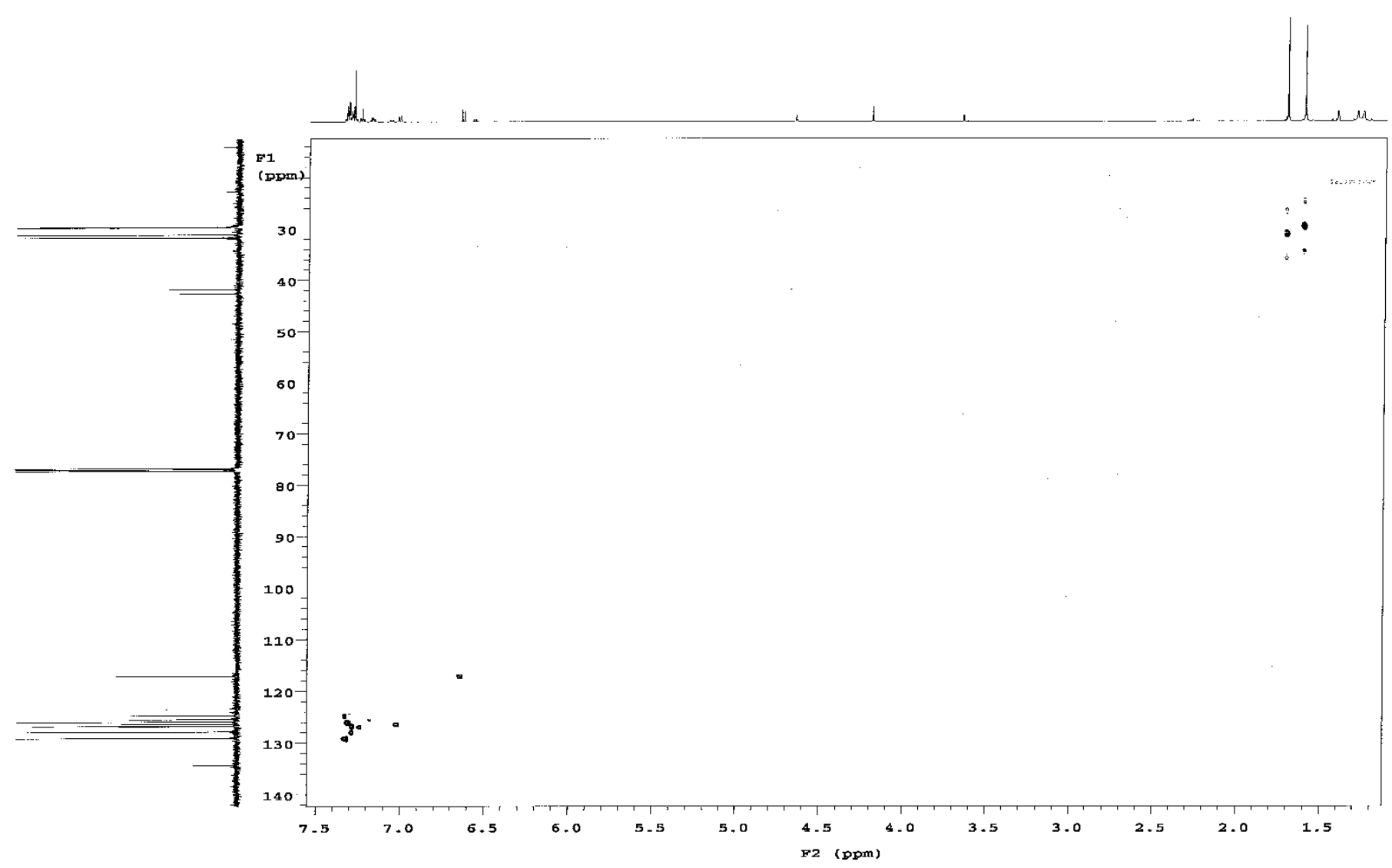

Figure S25. HMQC spectrum $\left(\mathrm{CDCl}_{3}, 500 \mathrm{MHz}\right)$ of 2,4-bis(1-methyl-1-phenylethyl)-phenol (3). 


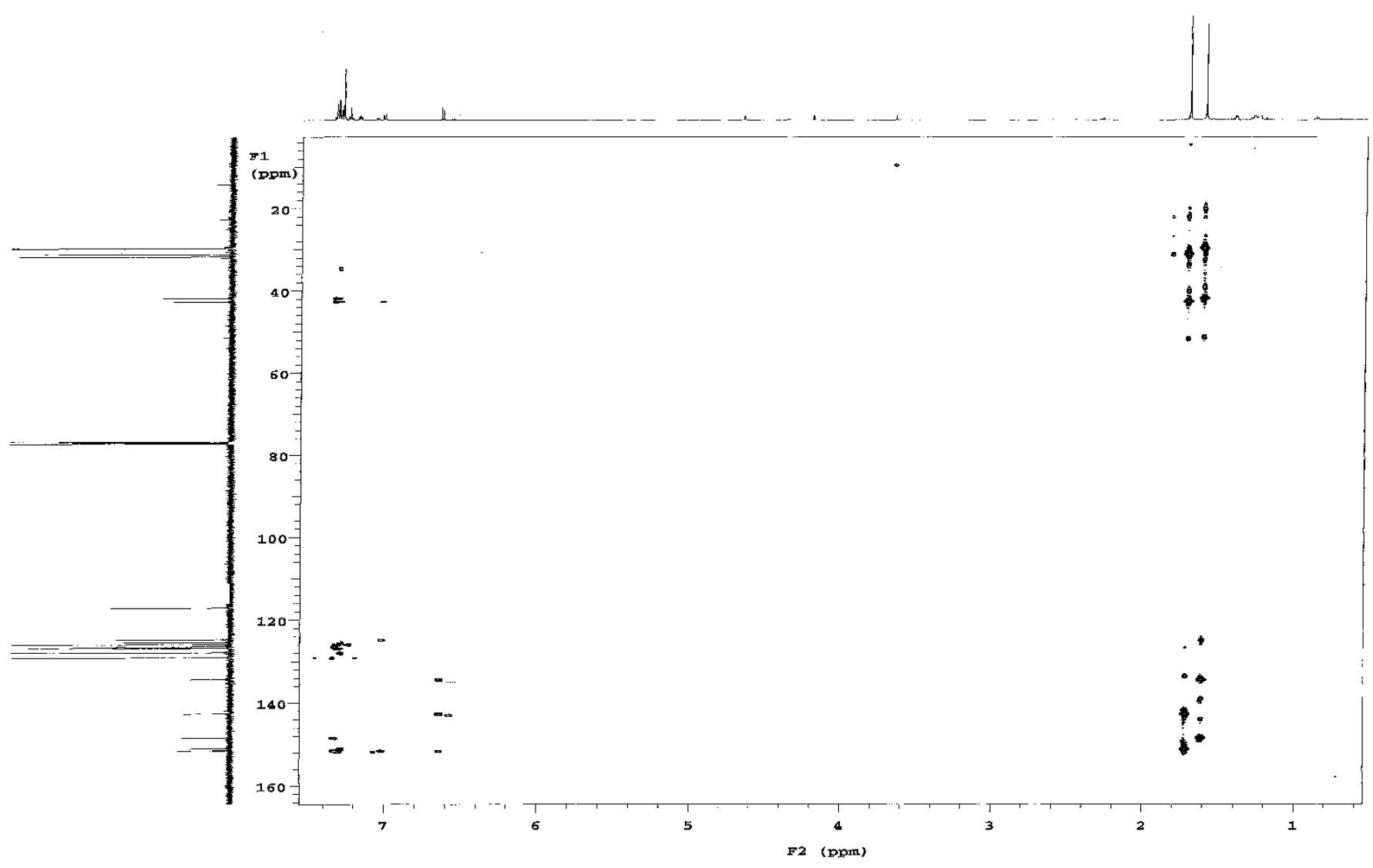

Figure S26. HMBC spectrum $\left(\mathrm{CDCl}_{3}, 500 \mathrm{MHz}\right)$ of 2,4-bis(1-methyl-1-phenylethyl)-phenol (3). 
Acq. Data Name: shaaban151216-1
Creation Parameters: Average(MS[1] Time:0.13.0.20)
Comment: Shaaban MSMY2
Relative Area

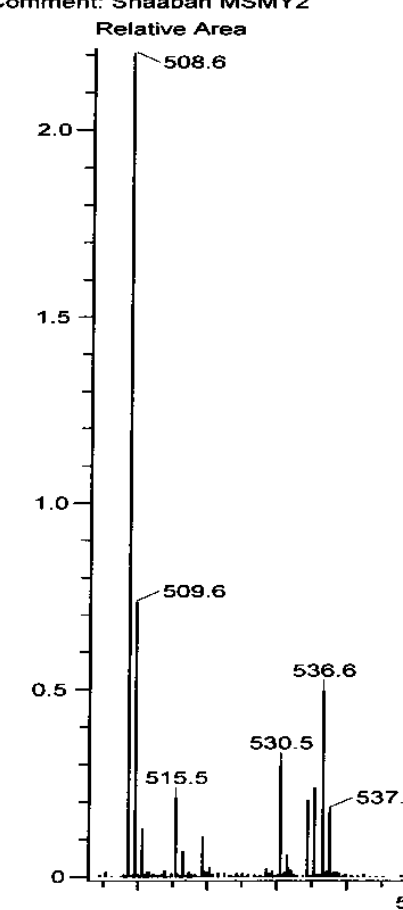

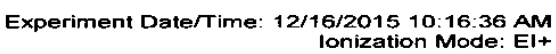

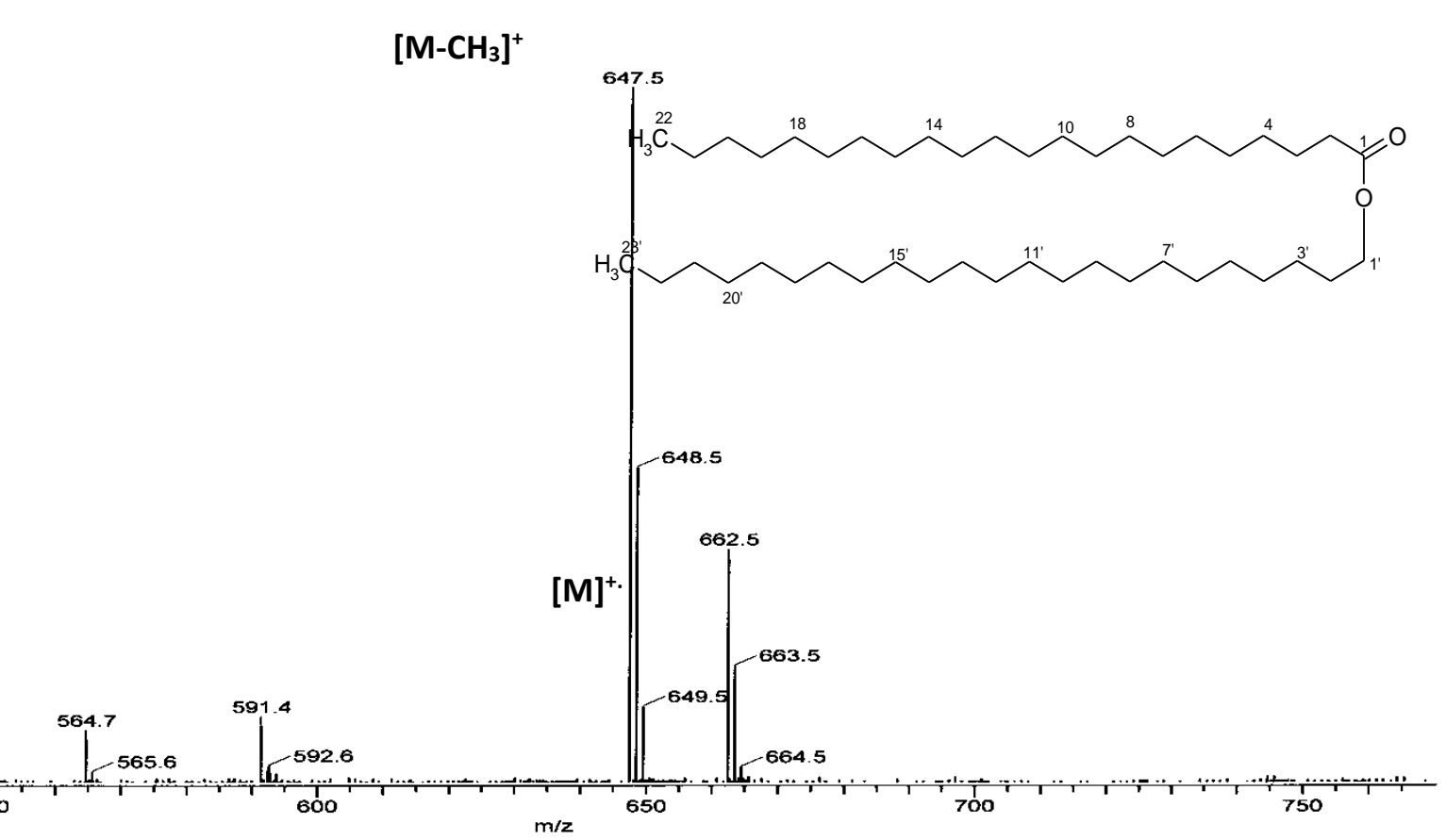

Figure S27. -EI MS spectrum of tricosyldocosanoiate (4). 
Acq. Data Name: shaaban151216-1

Creation Paramelers. Average(MS[1] Time:0.13..0.20)

Comment: Shaaban MSMY2

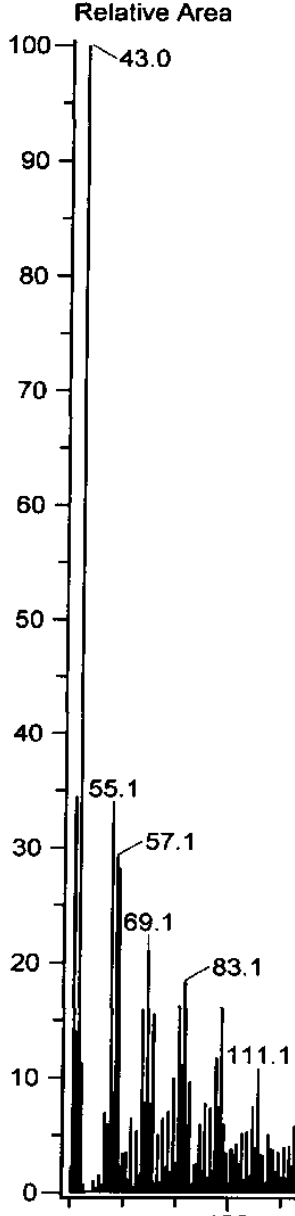

100
Experiment Date/Time: 12/16/2015 10:16:36 AM Ionization Mode: El+

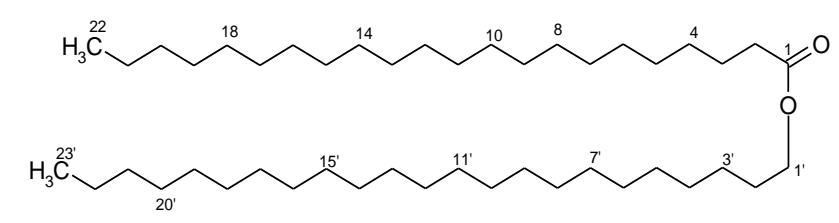

2573

$256.3-382.4$

\section{$\left[\mathrm{M}-\mathrm{CH}_{3}\right]^{+}$}

$\left.368.4\right|_{383.4} ^{382.4} \quad 480.5508 .6 \quad 647.5$ 

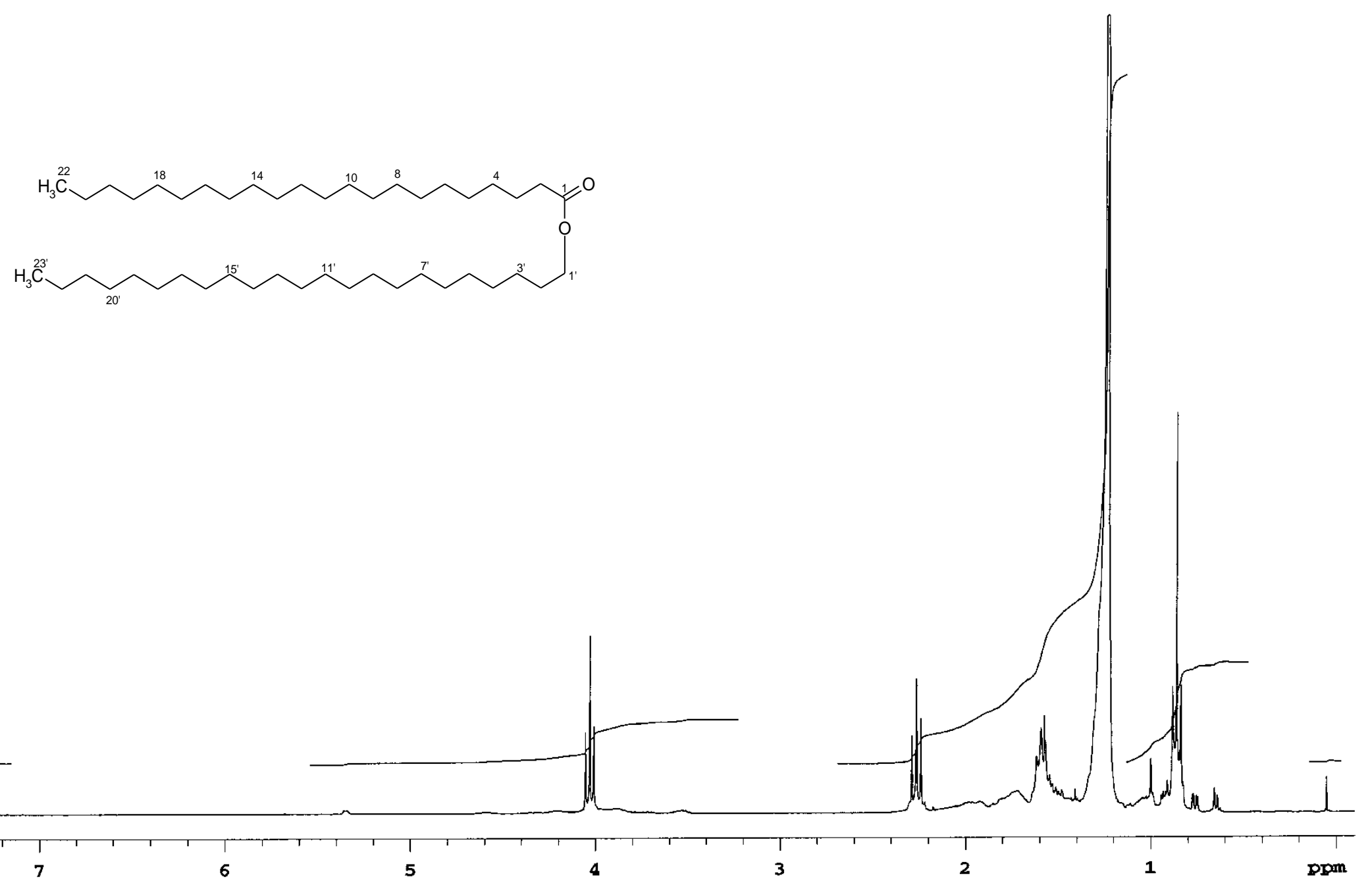

Figure S29. ${ }^{1} \mathrm{H}$ NMR spectrum $\left(\mathrm{CDCl}_{3}, 300 \mathrm{MHz}\right.$ ) of tricosyldocosanoiate (4). 

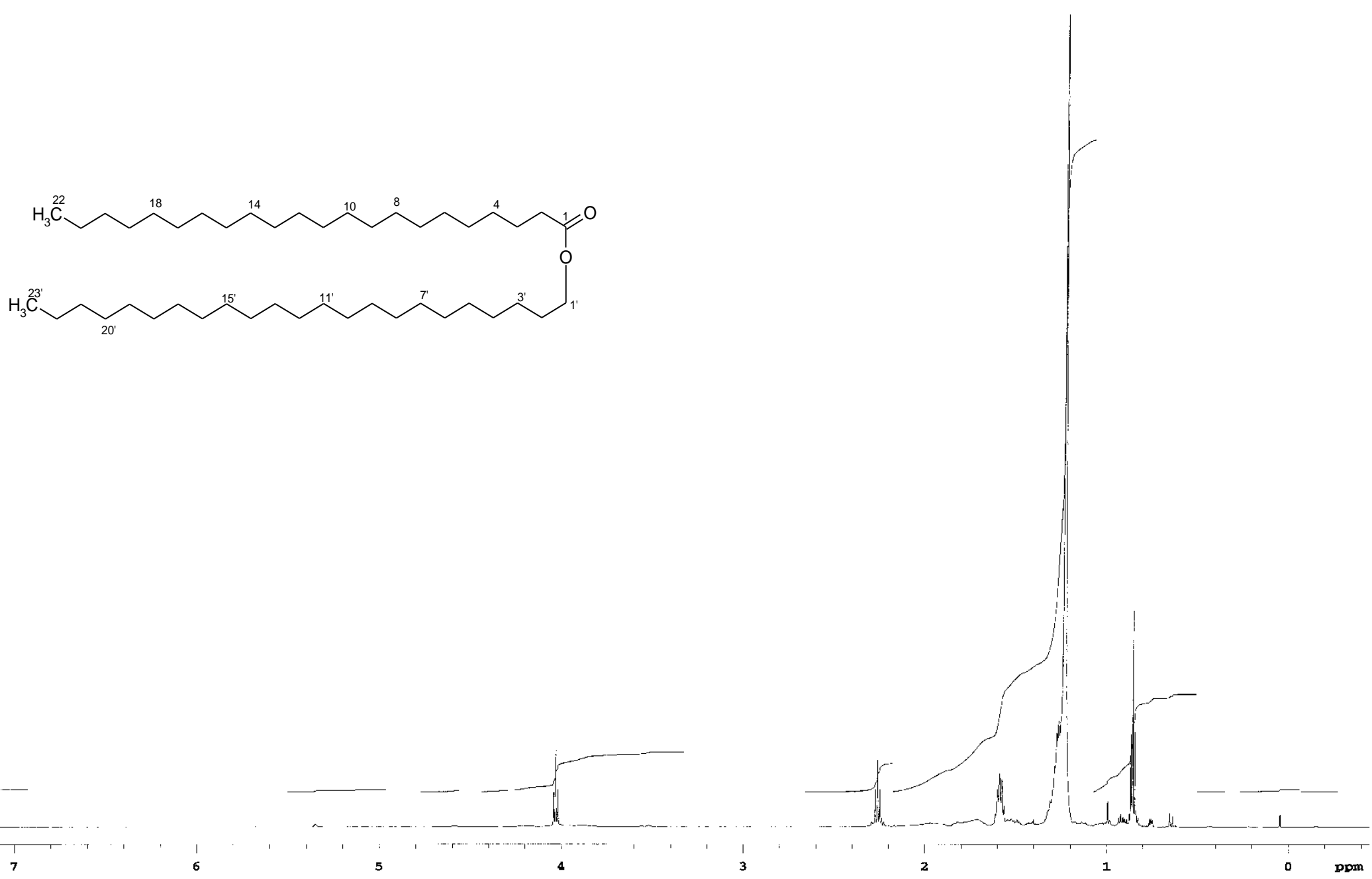

Figure S30. ${ }^{1} \mathrm{H}$ NMR spectrum $\left(\mathrm{CDCl}_{3}, 600 \mathrm{MHz}\right)$ of tricosyldocosanoiate (4). 


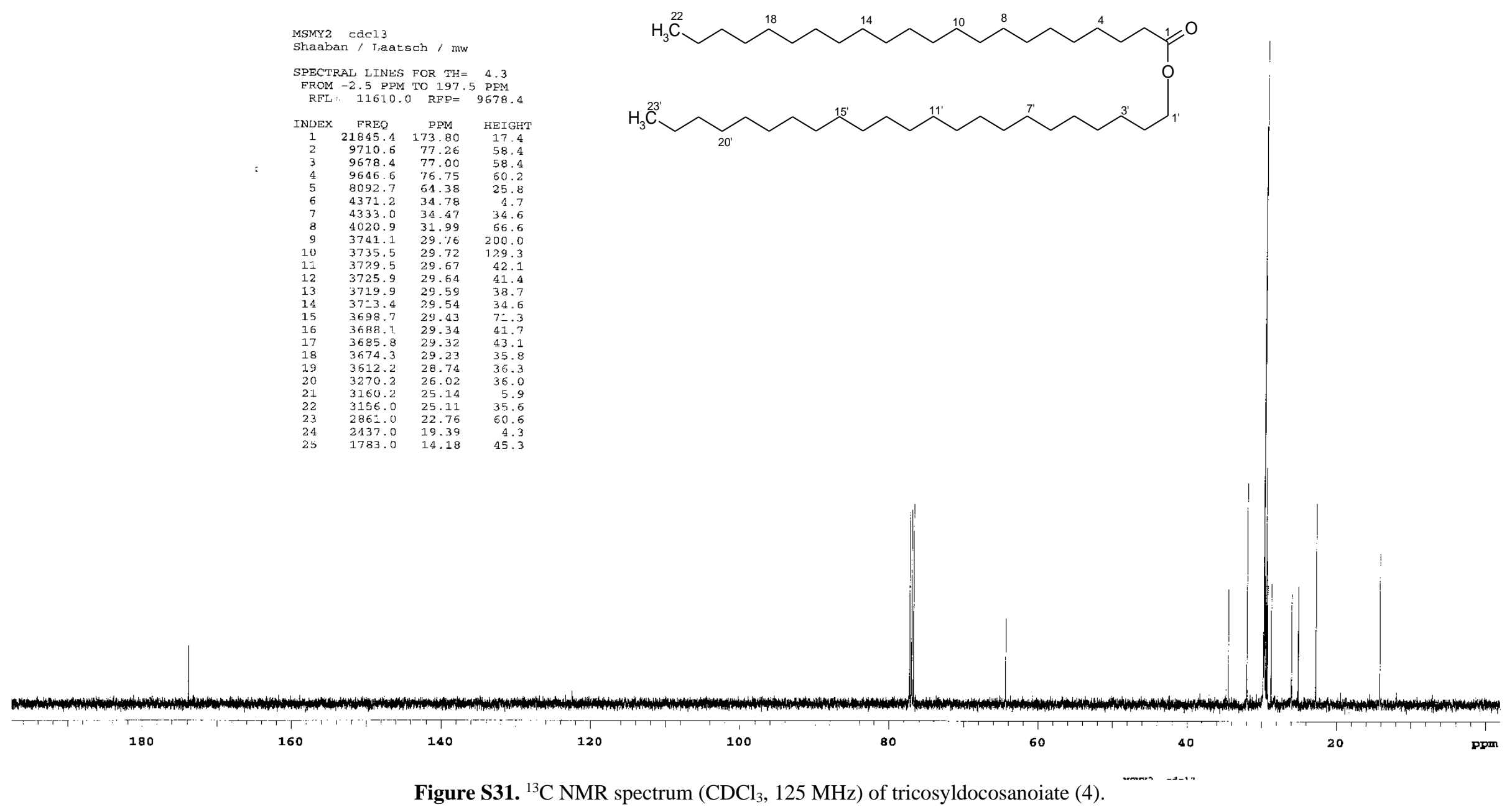




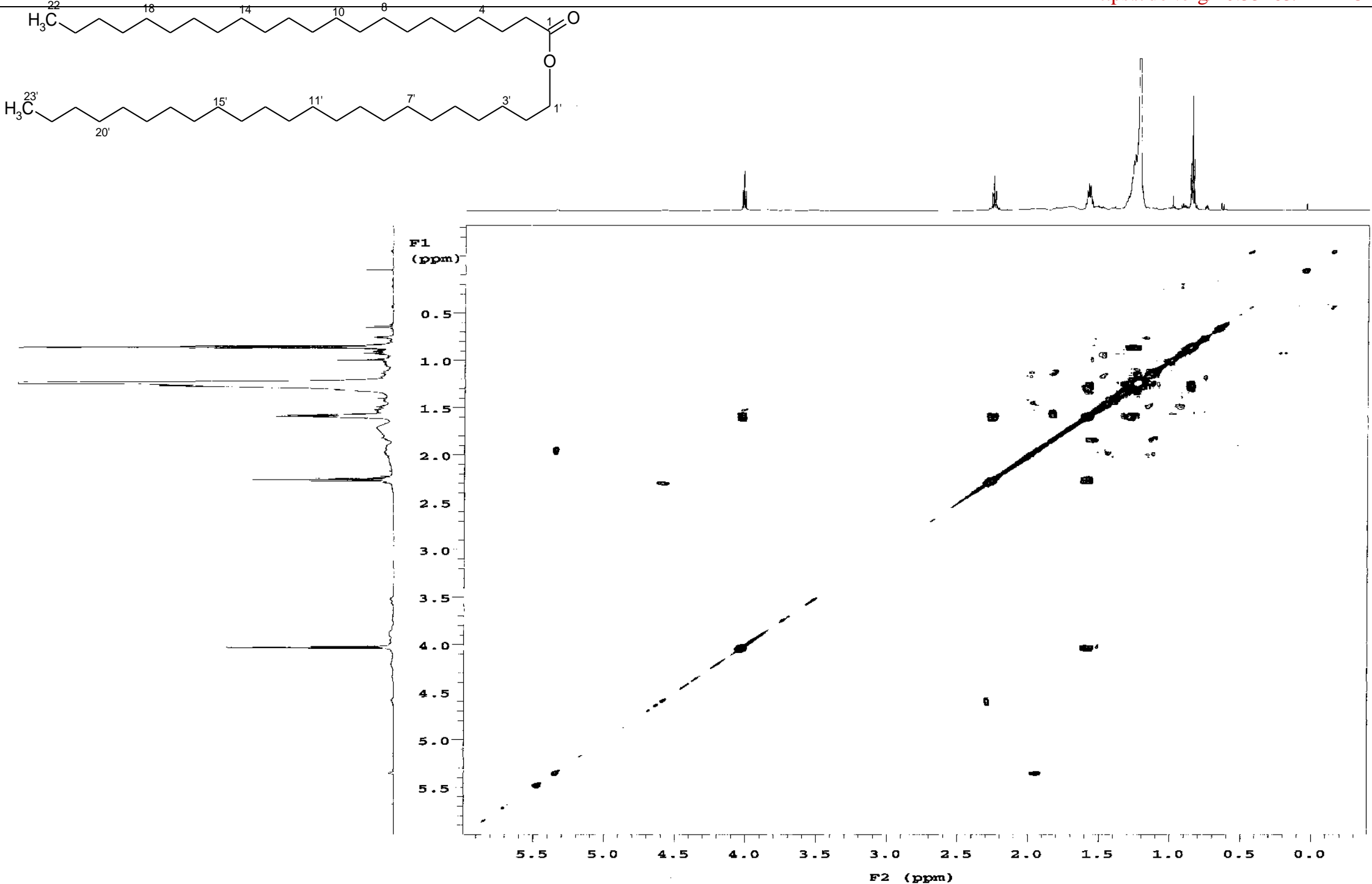

Figure S32. ${ }^{1} \mathrm{H}-{ }^{1} \mathrm{H}$ COSY spectrum $\left(\mathrm{CDCl}_{3}, 500 \mathrm{MHz}\right)$ of tricosyldocosanoiate (4). 


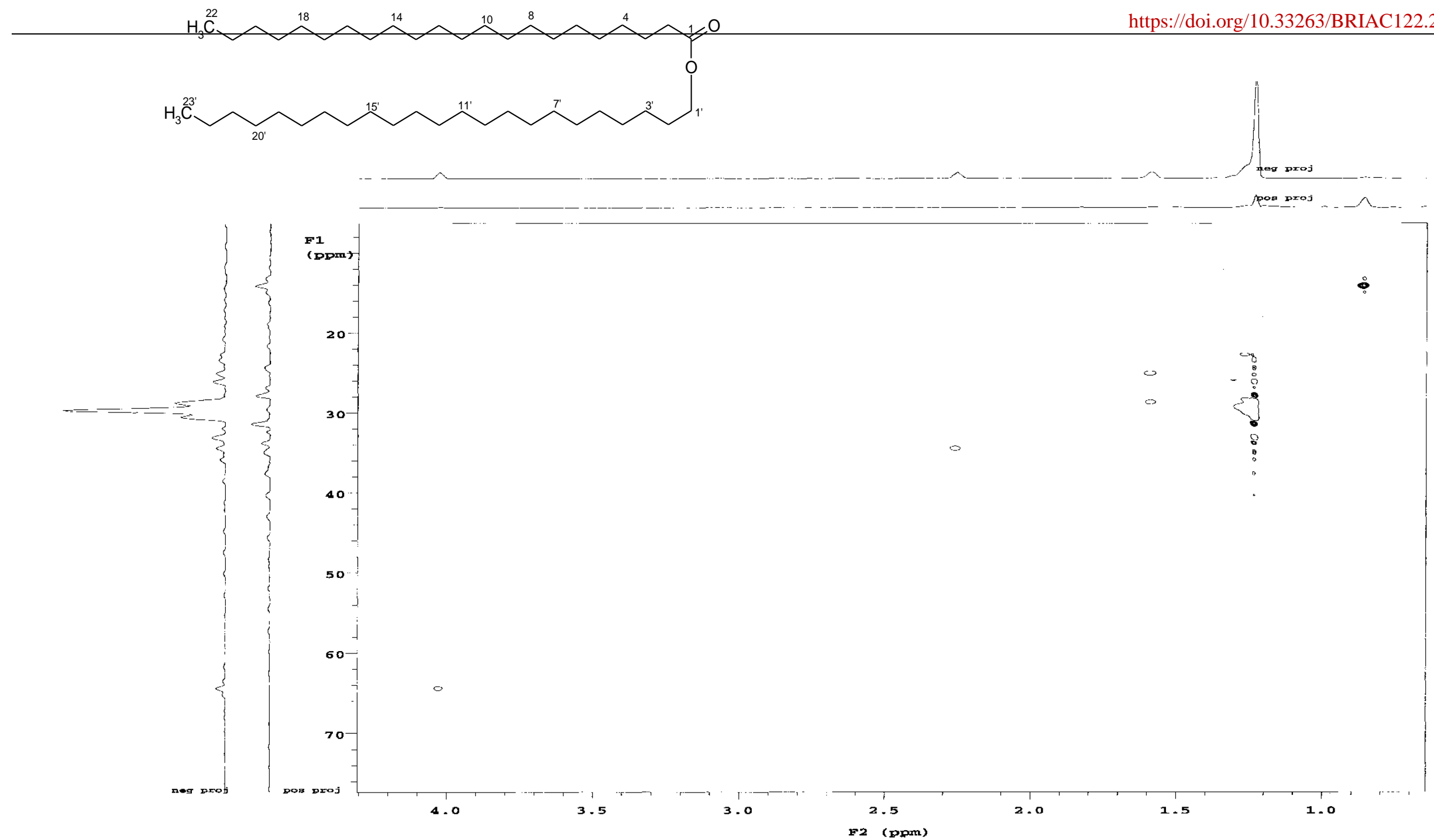

Figure S33. ${ }^{1} \mathrm{HSQC}$ spectrum $\left(\mathrm{CDCl}_{3}, 500 \mathrm{MHz}\right)$ of tricosyldocosanoiate (4). 


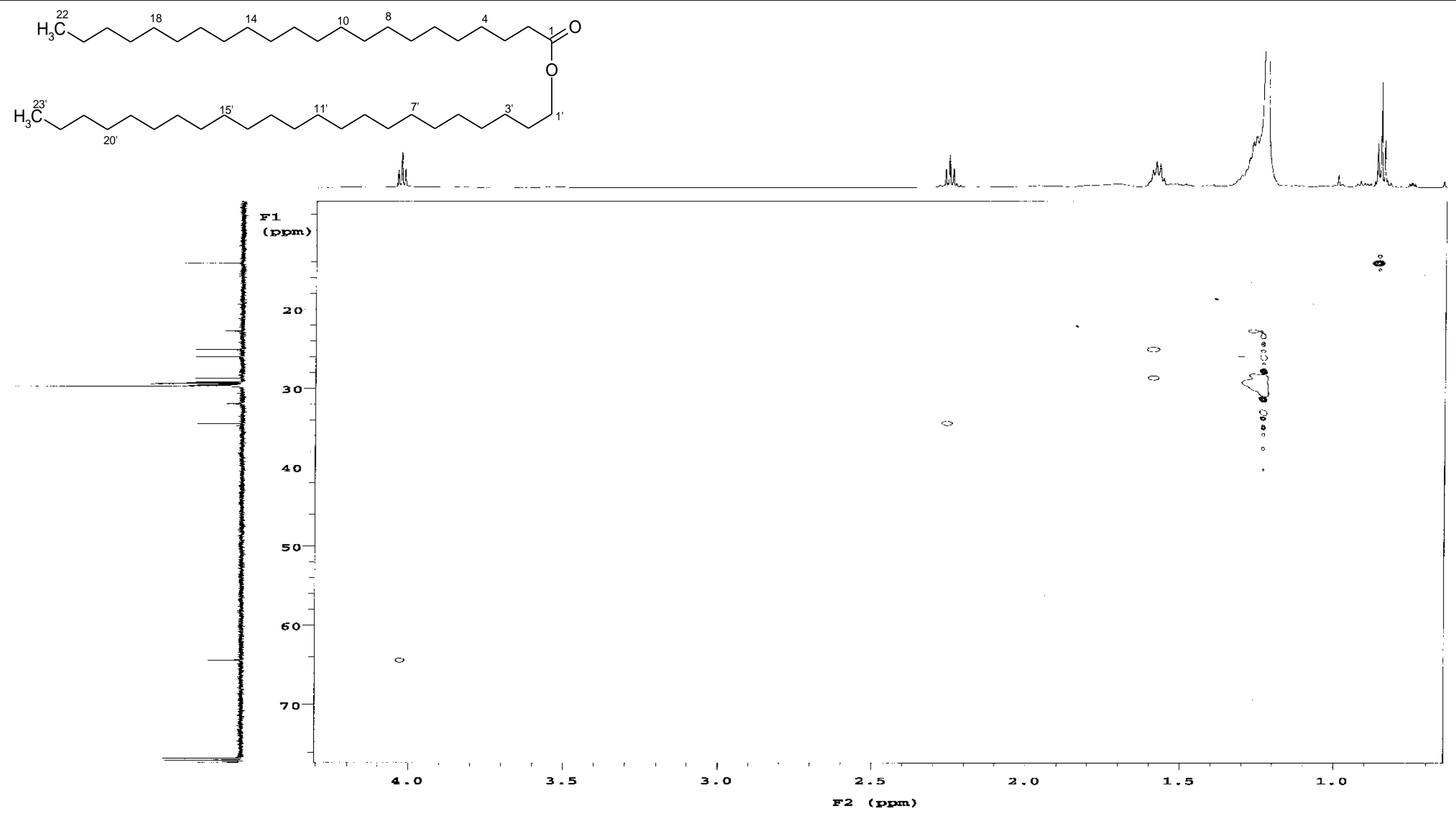

Figure S34. HMQC spectrum $\left(\mathrm{CDCl}_{3}, 500 \mathrm{MHz}\right)$ of tricosyldocosanoiate (4). 


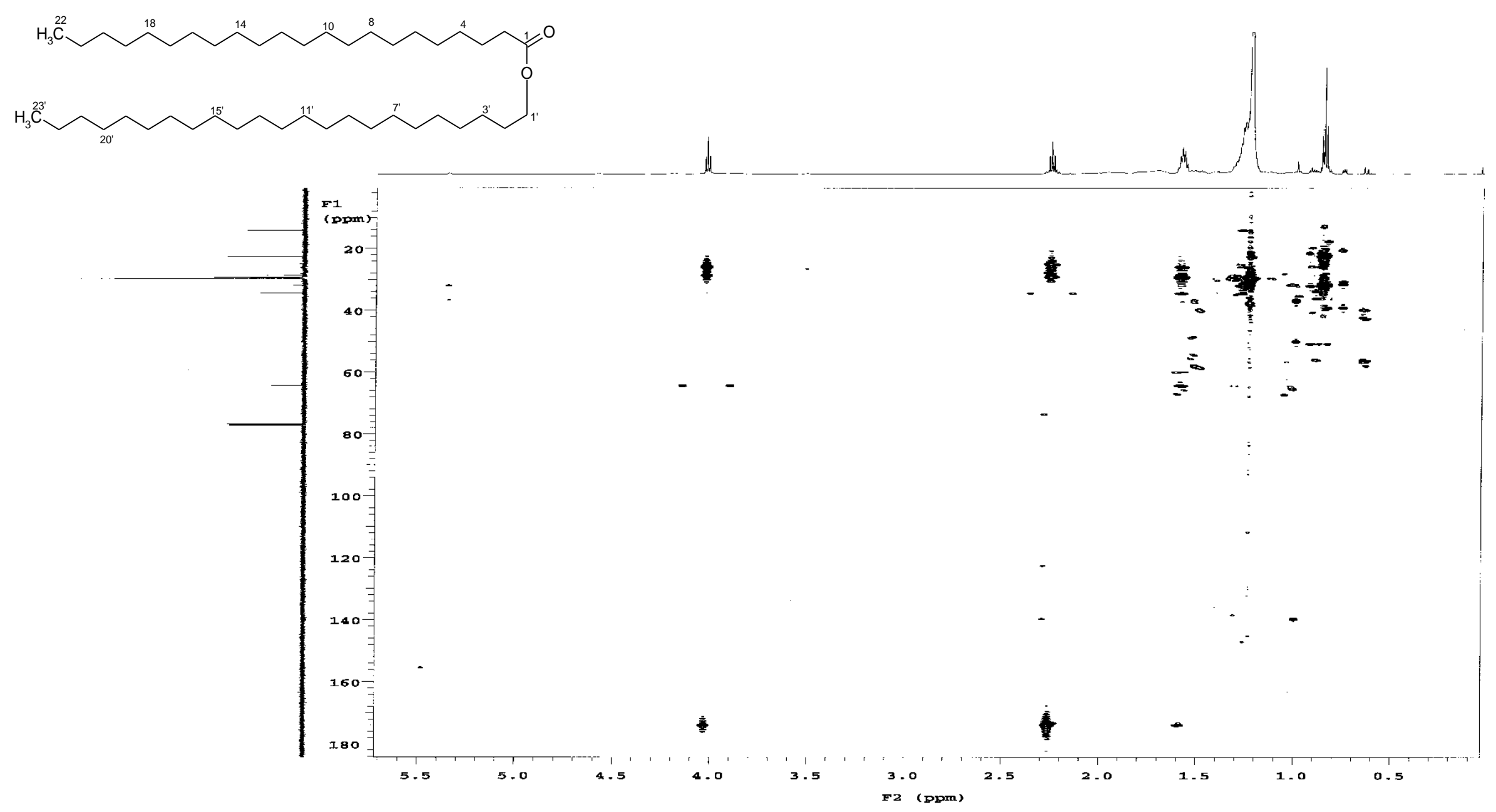

Figure S35. HMBC spectrum $\left(\mathrm{CDCl}_{3}, 500 \mathrm{MHz}\right)$ of tricosyldocosanoiate (4). 